DOI: $10.24850 / j-t y c a-2021-02-06$

Artículos

\title{
Dinámicas socioambientales y potencialidades turístico- recreativas del humedal de La Segua (Ecuador): actitudes y percepciones de los agentes locales y visitantes
}

\section{Socio-environmental dynamics and tourist-recreational potential of the La Segua wetland (Ecuador): Attitudes and perceptions of local agents and visitors}

Manuel Rivera-Mateos ${ }^{1}$, ORCID: https://orcid.org/0000-0003-2780-380X Neme Yamil Doumet-Chilán², ORCID: https://orcid.org/0000-00034295-5270

1Universidad de Córdoba, Córdoba, España, manuel.rivera@uco.es ²Escuela Superior Politécnica Agropecuaria, Manabí, Ecuador, doumetour@hotmail.com

Autor para correspondencia: Manuel Rivera-Mateos, manuel.rivera@uco.es 
Tecnología y

\section{Resumen}

En este trabajo se realiza una caracterización socioambiental del humedal de La Segua, Ecuador, como punto de partida para comprender los significados, valores, actitudes y motivaciones de los agentes, comunidades locales y visitantes que intervienen en este espacio protegido declarado Sitio Ramsar, en relación con la sostenibilidad de su gestión turístico-recreativa, y de los recursos naturales que le sirven de soporte. Con ello se busca establecer una serie de acciones futuras para su desarrollo y planificación de manera compatible con la recuperación de su ecosistema, actualmente con serios problemas de conservación y manejo de sus recursos territoriales; conflictos de usos del suelo y por el control del agua, y crisis de algunas de sus actividades tradicionales. El análisis realizado sigue una metodología mixta, cuantitativa y cualitativa, incluyendo un enfoque exploratorio y documental; se usaron encuestas estructuradas y entrevistas personales en profundidad semiestructuradas y parcialmente abiertas. Asimismo, se emplearon fuentes primarias obtenidas del trabajo de campo, que contó con el apoyo de una explotación SIG para georreferenciar los cambios de uso del suelo experimentados en las dos últimas décadas. Por último, se identifican diversos indicadores de base experimental para la toma de decisiones e implementación de medidas preventivas en materia de conservación y manejo sostenible del ecosistema del humedal, y para plantear lineamientos estratégicos de gestión turístico-recreativa de base comunitaria, que permitan, en su conjunto, el mantenimiento de relaciones socioculturales y ambientales de carácter sustentable. 


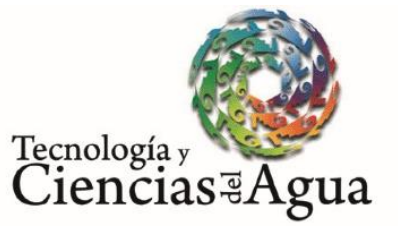

2021, Instituto Mexicano de Tecnología del Agua

Open Access bajo la licencia CC BY-NC-SA 4.0

(https://creativecommons.org/licenses/by-nc-sa/4.0/)

Palabras clave: zonas húmedas, turismo y recreación, caracterización socioambiental, sostenibilidad, humedal de La Segua, Ecuador.

\section{Abstract}

In this paper, a socio-environmental characterization of the La Segua wetland in Ecuador is carried out, trying to understand the meanings, values, attitudes and motivations of the agents, local communities and visitors that intervene in this protected area declared a Ramsar Site, in relation to sustainability of its tourist-recreational management and of the natural resources that serve as its support. With this, it seeks to establish a series of future actions for its development and planning in a manner compatible with the recovery of its ecosystem, currently with serious problems of conservation and management of its territorial resources, conflicts of land and water uses and crises of some of their traditional activities. The analysis carried out follows a mixed quantitative and qualitative methodology, including an exploratory and documentary approach and using structured surveys and in-depth semi-structured and partially open personal interviews. Likewise, primary sources obtained from field work have been used, which has had the support of a GIS exploitation to georeference the changes in land use experienced in the last two decades. Finally, various experimental-based indicators are identified for decision-making and implementation of preventive measures in the area of conservation and sustainable management of the wetland ecosystem and to propose strategic guidelines for communitybased tourist-recreational management, which allow for overall 


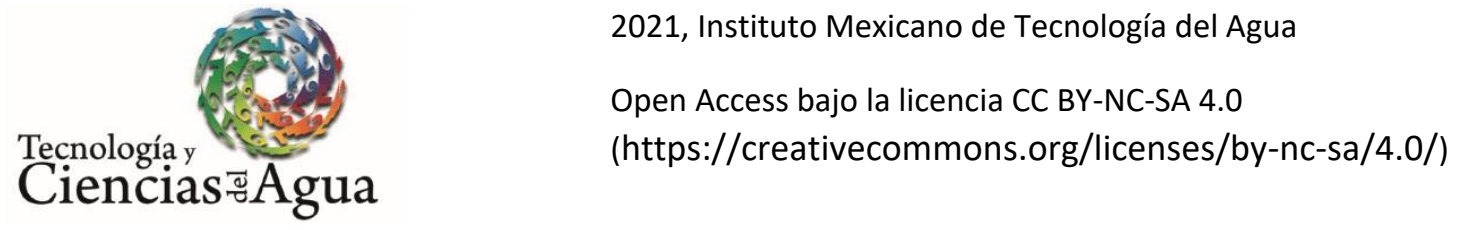

maintenance of socio-cultural and environmental relationships of a sustainable nature.

Keywords: Wetlands, tourism and recreation, socio-environmental characterization, sustainability, La Segua wetland, Ecuador.

Recibido: $22 / 04 / 2020$

Aceptado: $01 / 07 / 2020$

\section{Introducción}

La caracterización socioambiental de los espacios protegidos -percepción, valoración de la sostenibilidad-y las potencialidades turístico-recreativas de estos territorios por parte de los agentes locales y visitantes son dos instrumentos ciertamente útiles para la obtención de información directa para la adopción de estrategias adecuadas de planificación territorial y manejo sostenible de estas áreas protegidas. El diagnóstico socioambiental, la evaluación de los recursos territoriales y las potencialidades de estos espacios permite, en primer término, detectar las carencias, debilidades y limitaciones de los destinos de turismo de naturaleza y ecoturismo con fragilidad ambiental, como las zonas húmedas (Orgaz-Agüera, 2014; Sánchez-Carrillo, Álvarez-Cobelas, 


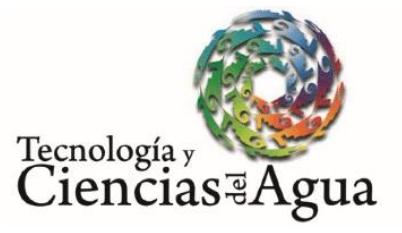

2021, Instituto Mexicano de Tecnología del Agua

Open Access bajo la licencia CC BY-NC-SA 4.0

(https://creativecommons.org/licenses/by-nc-sa/4.0/)

Cirujano, Carrasco-Redondo, \& Díaz-Cambronero, 2015); pero también resultan ser fundamentales para tener una prospectiva de los posibles conflictos de intereses entre los agentes, tanto externos como internos, implicados en dichos espacios, así como las divergencias entre usos y aprovechamientos del suelo; todo ello permite implementar las acciones de planificación necesarias para su minimización y reconducción (Jiménez \& Castillo, 2014; Cardozo, Fernández, Soares, \& Holm, 2016).

Numerosos estudios de caso (Chávez, 2007; Fernández, 2008; Fernández, Porter-Bolland, \& Sureda, 2010; Marín-Muñiz, HernándezAlarcón, Rivera, \& Moreno-Casasola, 2016) han demostrado, de hecho, que la percepción de los valores ambientales de cualquier territorio varía en función del uso y de los beneficios que practican y obtienen, respectivamente, los agentes locales en el medio natural. Conocer este criterio es muy necesario para identificar alternativas que mejoren el aprovechamiento de los recursos territoriales, tanto naturales como socioculturales, del área de influencia de estos espacios protegidos y a partir de ahí implementar estrategias que favorezcan su conservación, puesta en valor, y ordenación y planificación mediante políticas públicas que tengan en cuenta su característica patrimonial y su potencialidad como instrumento de desarrollo económico y bienestar social para las comunidades locales.

En las zonas rurales y suburbanas se tienen diferentes percepciones sobre el medio natural, el paisaje y el ambiente, fundadas por lo general en saberes, tradiciones y costumbres que son difíciles de comprender por quienes viven en regiones urbanas con patrones, reglas y modos de vida influenciados por el modelo de desarrollo socioeconómico occidental. Por 


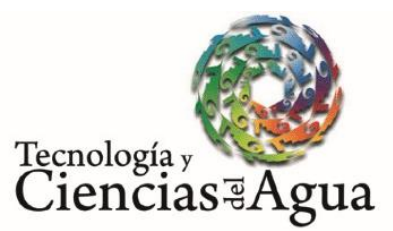

tanto, la búsqueda de alternativas de sostenibilidad para un buen manejo de los recursos territoriales de estas zonas rurales precisa de la caracterización previa de los modos de vida de sus poblaciones y de las problemáticas que éstas experimentan en sus conexiones con el medio natural.

Este tipo de diagnóstico de carácter territorial no debe reducirse, en cualquier caso, a los aspectos físico-ambientales y a los relativos a las actividades económicas que soportan estos espacios protegidos, como el turismo y la recreación, sino que también, y de manera precisa, han de incluir los aspectos socioambientales, intentando abordar, en definitiva, la realidad territorial desde un enfoque sistémico e integral (Varisco, 2016). Como señalan Konu y Kajala (2012), los diagnósticos y evaluaciones territoriales constituyen la base para desarrollar un análisis riguroso de fenómenos determinados, ofreciendo elementos, orientaciones y criterios para valorar la situación actual y de partida de cualquier área protegida, así como para identificar sus tendencias y dinámicas, y a partir de ahí generar conocimiento, buenas prácticas y lecciones aprendidas a la hora de proponer posibles acciones estratégicas de conservación y manejo.

El turismo, por otro lado, si bien tiene un carácter relevante en cuanto a impactos socioeconómicos, generación de empleo y nuevas actividades productivas, sobre todo en países pobres y en vías de desarrollo (Toselli \& Mazza, 2014), también puede provocar conmociones territoriales significativos, sobre todo en espacios de gran fragilidad ambiental, como los humedales; por tanto, debe desarrollarse siguiendo criterios de sostenibilidad mediante procesos de planificación integral de 


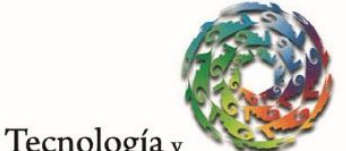 \\ Ciencias $\stackrel{\unlhd}{\triangle}$ Agua}

2021, Instituto Mexicano de Tecnología del Agua

Open Access bajo la licencia CC BY-NC-SA 4.0

(https://creativecommons.org/licenses/by-nc-sa/4.0/)

este tipo de territorios y la evaluación continua de los resultados de tal planeación durante la aplicación de una estrategia de gobernanza (VeraRebollo \& Díez-Santo, 2016; Puhakka, Pitkänen, \& Pirkko, 2016).

La sostenibilidad bien entendida no es otra cosa que la capacidad de los sistemas socioecológicos (SSE) de satisfacer las necesidades de la población actual y de las generaciones futuras, y de mantener en el tiempo sus actividades socioeconómicas, como el turismo, de manera compatible con la propia resiliencia frente a los impactos negativos en los ecosistemas y paisajes naturales y socioculturales (Martínez, Huber, Arredondo, Costero, \& Peña, 2012). No obstante, como señalan no pocos autores (Martínez, 2013), la sostenibilidad adolece aún de una conceptualización comúnmente aceptada, por tratarse de un término un tanto impreciso, etéreo, deformable y adaptable según el interés, por lo que ha acabado muchas veces por banalizarse o instrumentarse de forma inadecuada por discursos teóricos y políticos interesados que ni siquiera se han plasmado en acciones sustantivas que puedan calificarse en realidad como sostenibles. Puede afirmarse, incluso, que existen tantas propuestas de definición y gestión de la sostenibilidad como proyectos de desarrollo sostenible y éstos, además, no cuentan muchas veces con una gestión turística planificada capaz de superar la dicotomía "conservación versus desarrollo", y de fortalecer la equidad, la participación social efectiva, el desarrollo integral desde el respeto a los intereses generales de las comunidades locales, y la diversificación y pluriactividad económicas.

La planificación turística eficiente y sostenible en las áreas naturales sólo resulta posible, por lo demás, si se consigue involucrar a todos los 


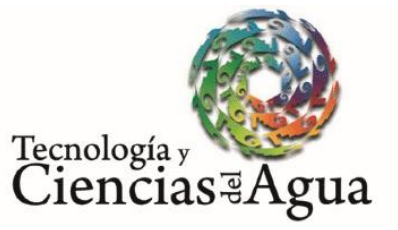

2021, Instituto Mexicano de Tecnología del Agua

Open Access bajo la licencia CC BY-NC-SA 4.0

(https://creativecommons.org/licenses/by-nc-sa/4.0/)

actores implicados $y$, en especial, a los que tienen que ver con la gestión y el establecimiento de políticas que fortalezcan el sector turístico de manera compatible con la preservación de los valores patrimoniales tanto naturales como socioculturales de tales espacios (Shone, Simmons, \& Dalziel, 2016). Cabe destacar, eso sí, que la existencia de políticas públicas que fomenten el desarrollo del turismo y las actividades recreativas en la naturaleza resulta ser insuficiente si no se acompañan de acciones bien meditadas en materia de conservación y sostenibilidad proactivas del territorio afectado. En este sentido, Malek y Powell (2017) manifiestan que el ecoturismo — como forma de turismo más propia de los espacios naturales protegidos-, si se gestiona de forma adecuada, debe involucrar necesariamente a todos los actores comunitarios, además de sensibilizarlos y capacitarlos para que lideren el manejo y la conservación de los recursos naturales de dichos territorios, que al fin y al cabo son los sistemas de soporte y cualificación de los atractivos turístico-recreativos del destino, por lo que representan un factor fundamental para la sostenibilidad de este último.

Entre estos recursos naturales, que además están asociadas con prácticas y paisajes socioculturales muy característicos, hemos de destacar los humedales como ecosistemas singulares que comparten tipologías terrestres y acuáticas y, por tanto, con la presencia de agua, suelos, vegetación, fauna, aprovechamientos económicos y paisajes modificados por el ser humano. El valor de estos humedales radica en sus múltiples funciones ecológicas y de suministro de servicios ecosistémicos de interés: áreas de reproducción y crianza de peces y de diversas especies acuáticas; de anidamiento y hábitat de avifauna; funcionamiento 


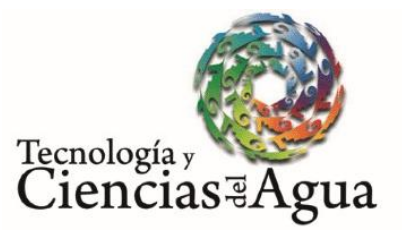

como barreras de protección contra tormentas y huracanes; condición de sistema de captura de carbono para mitigar el calentamiento global, proveer materia prima para la construcción y diversas actividades agrarias; sitios para el desarrollo de productos de recreación, educación ambiental y turismo de naturaleza, entre otros (Manson \& MorenoCasasola, 2007).

Los seres humanos a través del tiempo han aprovechado en mayor o menor medida tales servicios ambientales, pero el uso excesivo y los cambios de uso de suelo de estos ecosistemas por diversas actividades antrópicas han repercutido en su pérdida o deterioro; disminución de su biodiversidad; y transformaciones negativas en sus entornos, ecosistemas biofísicos y recursos naturales, como ha ocurrido en el caso que estudiamos. Al tratarse, por tanto, de ecosistemas generalmente sometidos a un largo proceso histórico de modificación por parte de los seres humanos, puede entenderse que el éxito de los planes de manejo sustentable de estos territorios dependa en buena parte de la implicación y sensibilización de las comunidades locales de sus áreas de influencia socioeconómica, y de su nivel de compromiso para cambiar algunos comportamientos y actitudes que puedan resultar negativos para la conservación y sostenibilidad ambiental de tales espacios (Carmona-Díaz, Morales-Mávil, \& Rodríguez-Luna, 2004; Moreno-Casasola et al., 2006). Por esto mismo resulta frecuente que dentro de la investigación social aplicada en estos territorios un paso esencial sea conocer cómo los individuos perciben su entorno e interactúan con él, para a partir de ello generar propuestas que contribuyan a la conservación ambiental, y el bienestar social y económico de las poblaciones locales afectadas. 
Tecnología y

El objetivo de este estudio se centra, en concreto, en esta línea de investigación, analizando un caso concreto: las comunidades locales de las áreas de San Antonio, La Segua, La Rea, La Sabana, en la provincia de Manabí, Ecuador, tradicionalmente muy vinculadas e influenciadas por el entorno de los ecosistemas del humedal La Segua, donde además de las actividades pesqueras y agrarias de mayor trayectoria histórica, han irrumpido en los últimos años, aunque todavía de forma tímida, las actividades de carácter turístico-recreativo.

Al tratarse este humedal de un ecosistema sumamente frágil desde el punto de vista ambiental y ya de por sí alterado desde antiguo, el desarrollo reciente de actividades turístico-recreativas en este espacio exige considerar previamente sus potencialidades reales y limitaciones de implantación sostenible en el entorno, así como su necesaria reorientación, según los casos, hacia prácticas más racionales, que minimicen al máximo sus impactos negativos y los conflictos de usos con otras actividades económicas. Para ello partimos de las tesis defendidas por autores como Holladay y Powell (2013), quienes estiman que el estudio del turismo en áreas naturales y sus implicaciones territoriales debe realizarse desde un enfoque integral y sistémico, donde se tome en cuenta, además de los recursos y paisajes naturales, otros recursos patrimoniales de carácter antrópico, como las prácticas socioculturales de los actores locales; el perfil de la demanda turística-recreativa; el sistema de gobernanza territorial y sus niveles de coordinación, en coherencia con las políticas públicas de gestión del turismo. Por último, también asumimos los planteamientos de autores como Scott, Cohen, Prayag y Moital (2014), los cuales inciden en que esos estudios de enfoque 


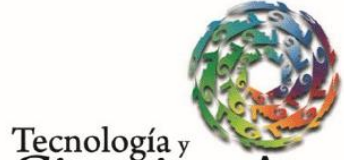

Teçnología y

Ciencias $₫$ Agua
2021, Instituto Mexicano de Tecnología del Agua

Open Access bajo la licencia CC BY-NC-SA 4.0

(https://creativecommons.org/licenses/by-nc-sa/4.0/)

integrador y sistémico deben tener en cuenta igualmente las percepciones, actitudes y motivaciones de los turistas y visitantes de estos espacios protegidos, con el objeto de articular una oferta que satisfaga sus necesidades, pero al mismo tiempo les sensibilice aún más en el respeto y valoración hacia el medio natural y sus comunidades locales, y facilite un uso y manejo adecuado del ecosistema natural de los humedales.

\section{El área objeto de estudio}

El objeto de esta investigación es el humedal de La Segua, ubicado entre los cantones de Chone y Tosagua, en la provincia de Manabí, Ecuador (Figura 1), caracterizado como zona húmeda con categoría internacional de sitio Ramsar desde el 7 de junio del año 2000 y como área protegida provincial más recientemente. El territorio principal de este espacio y el de mayor nivel de accesibilidad y conservación pertenece desde el punto de vista político-administrativo a la parroquia de San Antonio; tiene una extensión de 1745 ha. Se trata de una lámina de agua muy estacional, de manera que en la época seca se reduce a unas 525 ha. Cuenta, por lo demás, con una profundidad media de $67 \mathrm{~cm}$; altitud sobre el nivel del mar de unos 10 a $12 \mathrm{~cm}$; la temperatura media es de 26 a $27^{\circ} \mathrm{C}$. El humedal La Segua está integrado en el corredor hídrico Carrizal-Chone, 
en la región centro norte de la provincia de Manabí, y a pocos kilómetros de la desembocadura del río Chone, en la bahía de Caráquez.

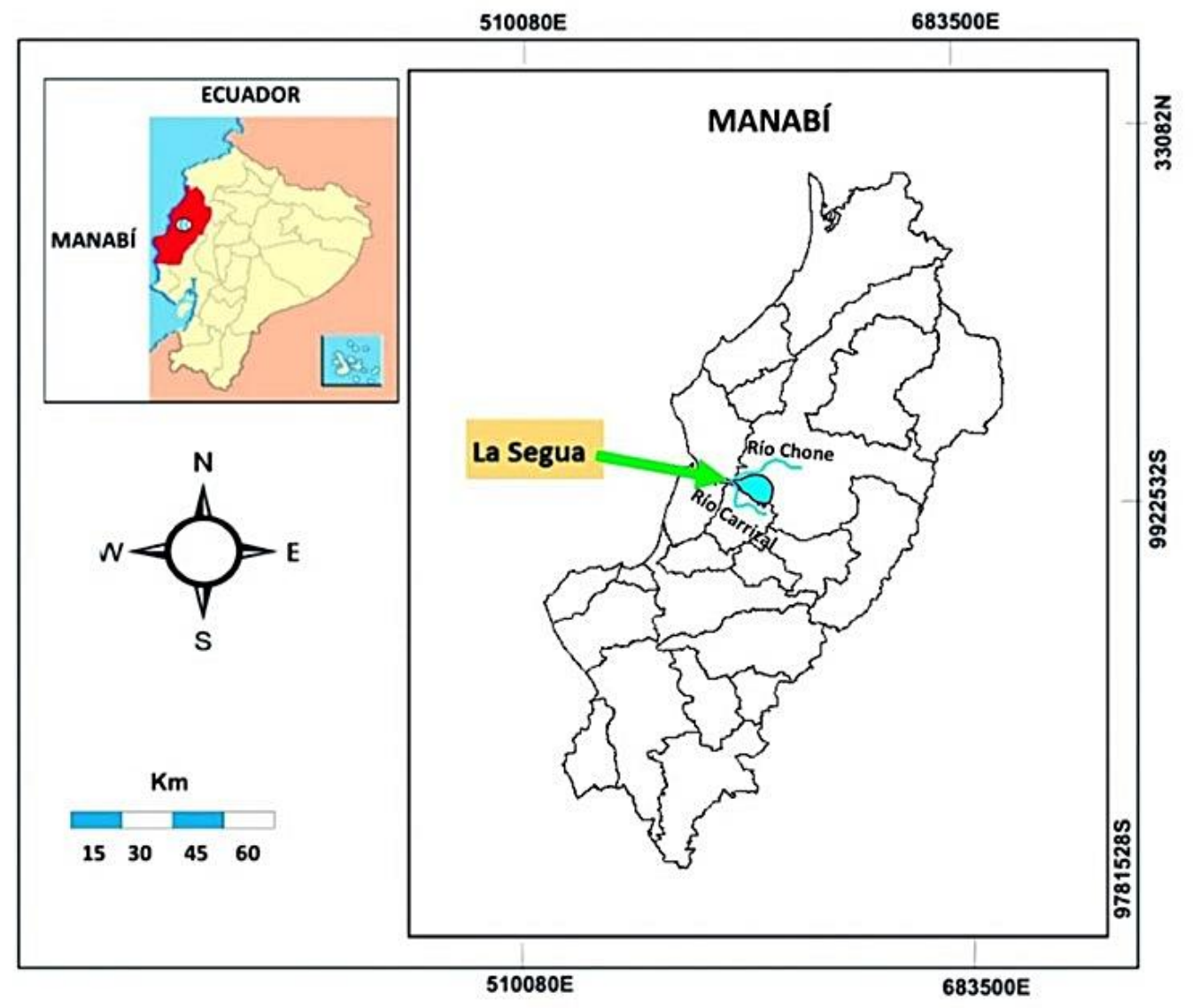

Figura 1. Mapa de localización geográfica del humedal La Segua. Fuente: base cartográfica del Ministerio del Ambiente de Ecuador (2014). Adaptación propia.

En el humedal La Segua existen no pocos recursos naturales y socioculturales de interés, pero por el mal uso del suelo y del agua que 


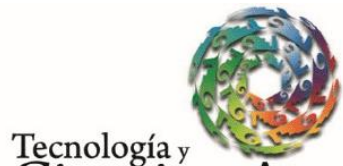

Ciencias đagua
2021, Instituto Mexicano de Tecnología del Agua

Open Access bajo la licencia CC BY-NC-SA 4.0

(https://creativecommons.org/licenses/by-nc-sa/4.0/)

se ha venido haciendo, en particular en las últimas décadas (camaroneras, agricultura intensiva, ganadería, uso de agrotóxicos, introducción de especies exóticas, etc.), esta zona tiene diversas afecciones territoriales que la han conducido a la pérdida de biodiversidad, contaminación de sus aguas y a una situación de crisis de sus actividades agrarias tradicionales, que han provocado un éxodo rural importante (Doumet, Rivera, \& García, 2018).

\section{Metodología y herramientas de trabajo}

En este estudio se realizó una caracterización socioambiental del humedal y su entorno territorial, para lo cual se hizo trabajo de campo in situ, que permitió el levantamiento de una serie de fichas de diagnóstico socioambiental de los recursos patrimoniales principales. El análisis fue básicamente de tipo exploratorio y documental, y se basó en métodos y herramientas de trabajo tanto cuantitativas como cualitativas. Para el desarrollo del proceso de investigación se partió de fundamentos teóricos y metodológicos ya contrastados en diversas investigaciones, y estudios de caso analizados en la revisión bibliográfica sobre planificación y gestión de zonas húmedas (Nunes-da-Cunha, Fernández, \& Junk, 2014; Ministerio del Ambiente de Ecuador, 2013; Ministerio del Ambiente de Ecuador, 2014; Secretaría de la Convención Ramsar, 2016). 


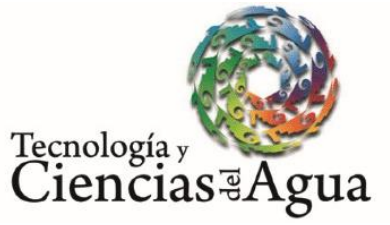

Tras el análisis de los antecedentes de investigación y las metodologías empleadas en diversos estudios de caso, se optó por un procedimiento metodológico adaptado a la realidad del área investigada por medio de tres fases secuenciales:

1. Un análisis interno del humedal utilizando tanto fuentes primarias como secundarias con la consulta de diversas plataformas de datos y repositorios de documentos oficiales, revistas científicas y técnicas especializadas para fundamentar la investigación, previa clasificación, ordenación y análisis sistemático de la información obtenida. La caracterización territorial tuvo en cuenta los aspectos sociales, ambientales, ecológicos y económicos, así como los socioculturales y turísticos. Además de las visitas practicadas en el trabajo de campo, se hicieron encuestas, aplicando un total de 50 cuestionarios a la población y actores locales de las cuatro comunidades del área de influencia del humedal (San Antonio, La Segua, Larrea, La Sabana). Las 10 preguntas del cuestionario tuvieron como eje principal la percepción sobre la situación ambiental y turística del humedal, y el nivel de sensibilización sobre los servicios ecosistémicos prestados.

Para el análisis de la gestión turística-recreativa y ambiental realizada en este humedal se usó una matriz con 17 indicadores de sostenibilidad, seleccionados tras aplicar entrevistas directas y en profundidad a 10 gestores, expertos y stakeholders locales y regionales correspondientes a diferentes instituciones implicadas, o con competencias directas o indirectas en la gestión pública de espacios protegidos (Ministerios del Ambiente y Turismo del Ecuador; GAD provincial de Manabí; Gobiernos Autónomos Descentralizados de Chone y 
Tecnología y
Ciencias Agua

parroquia San Antonio; Asociación Ecoturística de Guías Naturalistas del Humedal La Segua ASOHUMEDAL; BirdLife Ecuador; Comité de Gestión de los Pescadores del Humedal de La Segua y Asociados). Asimismo, se adoptó como metodología de referencia la de los trabajos del Ministerio del Ambiente de Ecuador: Manual para la gestión operativa de las áreas protegidas del Ecuador (Ministerio del Ambiente de Ecuador, 2013) y Evaluación de efectividad de manejo del patrimonio de áreas naturales (Ministerio del Ambiente de Ecuador 2014). Hay que destacar también que se consideraron algunos estudios de caso donde se obtuvieron resultados significativos en la aplicación de indicadores de turismo sostenible (OMT, 2018). En concreto, la evaluación de la situación del área de estudio necesitó de una matriz por indicadores que los clasificó en cuatro ámbitos de análisis fundamentados en los programas de manejo ya estandarizados en el país (gestión general del espacio protegido, sostenibilidad ambiental, sostenibilidad sociocultural y sostenibilidad económica), estableciéndose un sistema de indicadores ponderados en tres niveles: alto (A), medio (M) y bajo (B). La propuesta metodológica consideró finalmente seis áreas de gestión de este espacio protegido, que aparecen recogidas en la propia matriz del cuestionario (administración; control y vigilancia; planificación, desarrollo comunitario y educación ambiental; turismo y uso público; y conservación de la biodiversidad).

Por último, se procedió al levantamiento de una cartografía georreferenciada de evolución de usos del suelo mediante SIG, instrumentos GPS, y empleo de imágenes de satélite para el periodo 1998-2018 (Figura 2), con el objeto de identificar las tendencias y dinámicas territoriales recientes de este espacio. Para realizar dicho 
Tecnología y

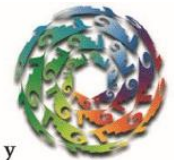

Ciencias ฐ̊Agua
2021, Instituto Mexicano de Tecnología del Agua

Open Access bajo la licencia CC BY-NC-SA 4.0

(https://creativecommons.org/licenses/by-nc-sa/4.0/)

análisis multitemporal se emplearon dos imágenes Landsat 5 y 8 con resolución de 30 m, tomadas en agosto de 1998 y septiembre de 2018, respectivamente, para cada zona de estudio en un lapso de 20 años. Dichas imágenes se obtuvieron desde el servidor de la USGS (Centro Geológico de los Estados Unidos) y se sometieron a correcciones radiométricas, geométricas y topográficas.
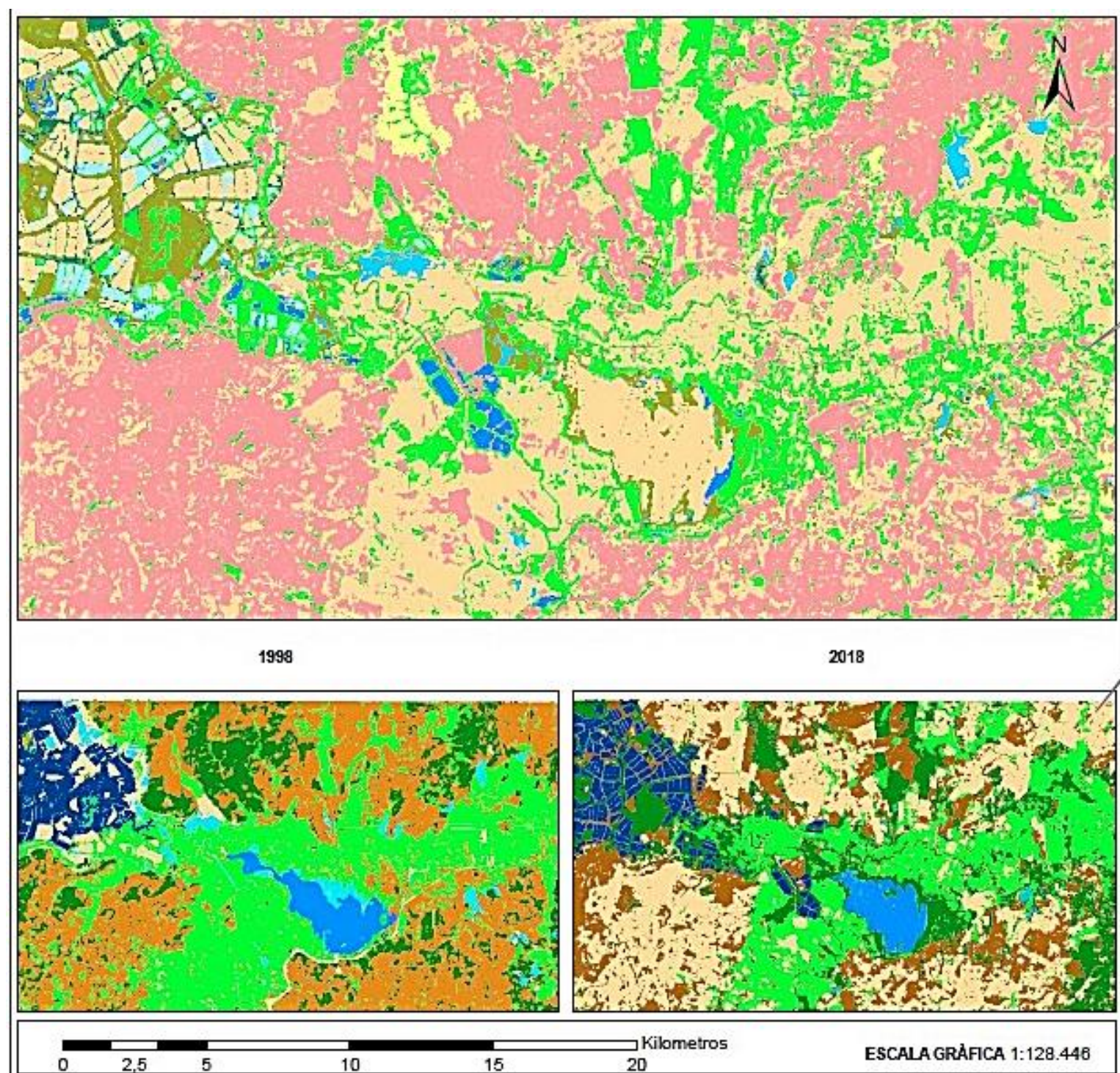

2,5

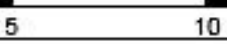

10

15

20

2018

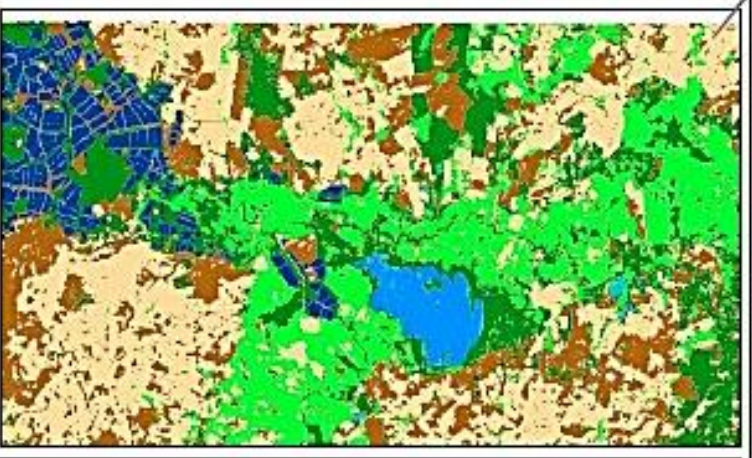

ESCALA GRÄFICA 1:128.446

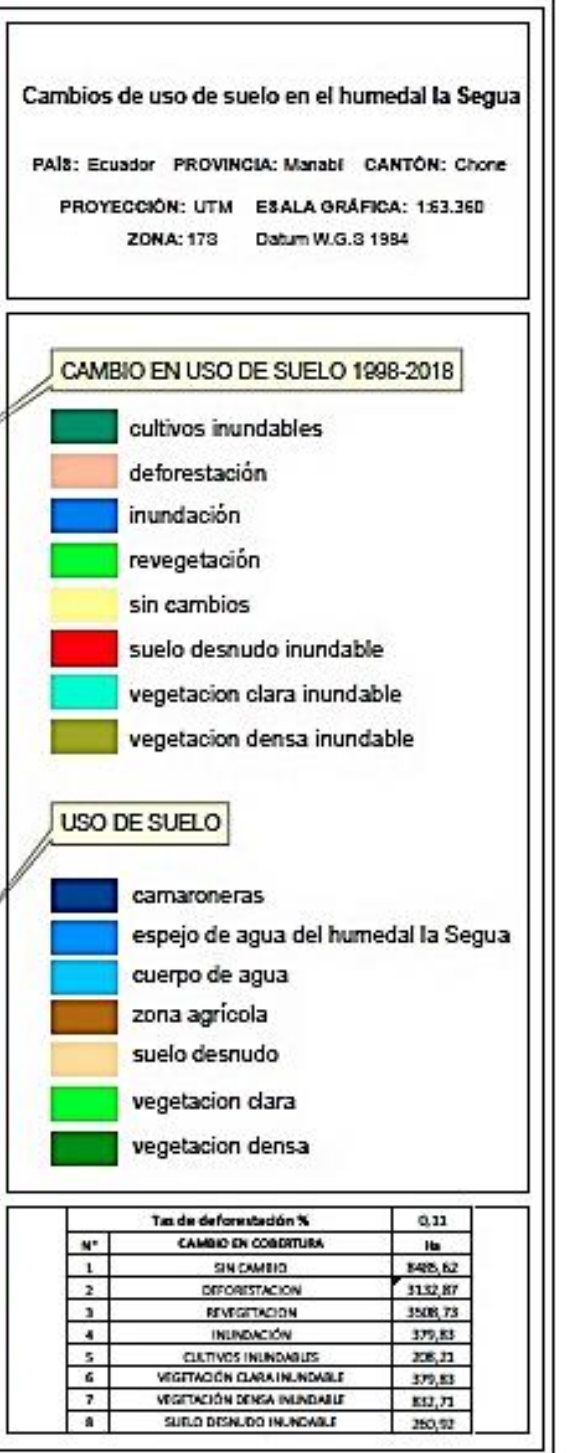




\section{6roty \\ Teçnología y \\ Ciencias $₫$ Agua}

2021, Instituto Mexicano de Tecnología del Agua

Open Access bajo la licencia CC BY-NC-SA 4.0

(https://creativecommons.org/licenses/by-nc-sa/4.0/)

Figura 2. Mapa de cambios de usos del suelo en el humedal de La Segua (1998-2018). Fuente: elaboración propia a través de SIG e imágenes de satélite.

2. En una segunda fase se hizo un análisis externo centrado en el estudio del perfil y de las características de la demanda de visitantes del humedal, a través de encuestas utilizando un cuestionario que incluyó algunas preguntas para conocer su valoración, actitudes, niveles de satisfacción y motivaciones de la visita en relación con este espacio protegido. Este análisis se justifica — de acuerdo con otros estudios similares ya contrastados (Scott et al., 2014) - por la importancia de obtener información de primera mano sobre el comportamiento, percepciones y tendencias de los consumidores que se sienten atraídos por estos destinos turísticos. Mediante dicha encuesta se pudieron detectar también los recursos territoriales turísticos más valorados por estos visitantes $y$, en principio, con mayores potencialidades turísticas, así como las insuficiencias del territorio en materia de equipamientos, infraestructuras, y sistemas de soporte y apoyo a las actividades turísticorecreativas más demandadas.

Para determinar el tamaño de la muestra se utilizó la metodología propuesta por Alatorre y Pérez (2011), partiendo de la consideración de una población infinita, pues las estadísticas oficiales existentes sobre el número de turistas y excursionistas que visitan el territorio son prácticamente inexistentes; los conteos de visitantes son, a su vez, poco rigurosos en lo subregional y local; y tampoco se tienen estudios previos de carácter científico sobre el volumen aproximado de visitantes. 


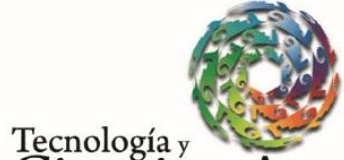

Ciencias ฐgua
2021, Instituto Mexicano de Tecnología del Agua

Open Access bajo la licencia CC BY-NC-SA 4.0

(https://creativecommons.org/licenses/by-nc-sa/4.0/)

Finalmente se aplicaron 196 cuestionarios como tamaño de la muestra, con un nivel de confianza del $95 \%$, un margen de error de $+/-3.85 \%$, y una varianza del 50 \%. Los datos recogidos se organizaron, tabularon y analizaron con el programa SPSS versión 21. Para esta encuesta se empleó un cuestionario de 18 preguntas estructuradas, en su mayor parte cerradas, distribuido en diferentes puntos estratégicos de mayor afluencia de visitantes en las áreas de Manta, Canoa y Portoviejo durante los meses de septiembre y octubre de 2018, en función de los resultados del trabajo de campo previo realizado y los contactos con agentes locales para identificar estos puntos de mayor número de visitantes.

3. Con los resultados obtenidos de las fases anteriores se lograron algunas lecciones aprendidas para establecer lineamientos que orienten el manejo adecuado del humedal de La Segua y su conservación; se determinaron acciones y proyectos que puedan servir como herramientas para la sostenibilidad. Se tuvo en cuenta, asimismo, la tesis de la OMT (2018) de que para desarrollar una planificación en áreas sensibles se deben establecer programas y proyectos que integren políticas de gestión local, regional y nacional, además de considerar a los actores locales y emprendedores, así como los factores ambientales, socioculturales y económicos de manera integral. La información resultante de las acciones planteadas se sintetizó en una matriz.

\section{Resultados}


Los resultados del estudio de caracterización socioambiental del humedal de La Segua y su área de influencia socioeconómica se sintetizan en la Tabla 1, donde se indican los aspectos más destacables extraídos de las encuestas a la población local y los visitantes; las entrevistas a agentes cualificados; el trabajo de campo, y la observación de participantes en la zona de estudio.

Tabla 1. Aspectos socioambientales principales de La Segua. Fuente: elaboración propia a través de encuestas, trabajo de campo y SIG.

\begin{tabular}{|l|l|}
\hline $\begin{array}{c}\text { Aspectos } \\
\text { territoriales }\end{array}$ & \multicolumn{1}{|c|}{ Características } \\
\hline \multirow{5}{*}{ Socioeconómicos } & $\begin{array}{l}\text { El } 47 \% \text { de los habitantes del área de influencia del } \\
\text { humedal se dedica a la pesca mediante la técnica del } \\
\text { trasmallo (red o cerca de bambú). El } 17 \% \text { de la } \\
\text { población realiza labores agrícolas, siendo las más } \\
\text { importantes las relativas a los cultivos de maíz, plátano, } \\
\text { tomate, pepino, haba, sandía, pimiento, fréjol (frijol) y } \\
\text { melón; mientras que un 20 \% desarrolla actividades } \\
\text { pecuarias, y otro } 20 \%, \text { aproximadamente, se dedica a } \\
\text { la acuicultura tradicional de camarones o la de más } \\
\text { reciente valor comercial de especies exóticas de tilapias } \\
\text { El 95 \% de los habitantes encuestados indicó que } \\
\text { contaba con servicio de energía eléctrica, y un } 73 \% \\
\text { manifestó que no utilizaba directamente el agua } \\
\text { proveniente del humedal en sus actividades diarias, }\end{array}$ \\
\hline
\end{tabular}




\begin{tabular}{|c|c|}
\hline & $\begin{array}{l}\text { pues las comunidades poseen servicio público de } \\
\text { abastecimiento de agua potable; al menos el } 27 \% \\
\text { restante usaba el agua del humedal para el riego de } \\
\text { cultivos, atención de la ganadería y la cría de } \\
\text { camarones } \\
\text { La situación del servicio público de alcantarillado y } \\
\text { evacuación de aguas residuales es, en cambio, muy } \\
\text { deficitaria, pues tan sólo el } 3 \% \text { de los hogares cuenta } \\
\text { con este servicio de alcantarillado; la mayor parte de la } \\
\text { población construye pozos ciegos y letrinas, con los } \\
\text { consecuentes problemas de contaminación de } \\
\text { acuíferos. } \\
\text { Hay } 95 \% \text { de luz eléctrica en todas sus comunidades. } \\
\text { Por último, se cuenta en la zona con un subcentro de } \\
\text { salud ubicado en la cabecera parroquial y tres } \\
\text { dispensarios del seguro social campesino en las } \\
\text { comunidades locales de Bravos Chicos, San Pablo y } \\
\text { Barquero }\end{array}$ \\
\hline Ambientales y ecológicos & $\begin{array}{l}\text { El humedal es de agua dulce y se constituye por un } \\
\text { pantano central que casi siempre está anegado, así } \\
\text { como por una extensa llanura inundable que se cubre } \\
\text { de agua en la estación lluviosa } \\
\text { Su suelo es franco arenoso, limoso y/o arcilloso limoso, } \\
\text { generalmente profundo, con depósitos fluviales finos de } \\
\text { sedimentos recientes. } \\
\text { El agua es de mediana calidad, con presencia de } \\
\text { coliformes fecales y sólidos suspendidos totales y un } \\
\text { bajo porcentaje de oxígeno disuelto } \\
\text { Se han identificado en el trabajo de campo hasta } 12 \\
\text { especies de peces, dos de camarón de río }\end{array}$ \\
\hline
\end{tabular}


(Machrobrachyum americanum y Macrobrachyun tenellum); tortugas del género Chelydra; y 164 especies de aves, entre las cuales hay 22 especies migratorias y 63 acuáticas

La flora se compone de 27 familias y 39 especies de vegetación silvestre, y en la época lluviosa predominan las plantas acuáticas, en especial los lechuguines (Eichornia crassipens). En esta temporada, la ciénaga puede llegar a tener una profundidad promedio de hasta 1.27 metros Los problemas ambientales identificados están relacionados con los procesos de degradación y pérdida acelerada de hábitats por presiones antrópicas; desecación creciente; reducción de espejos de agua; uso inadecuado de los recursos hídricos superficiales por ampliación de los cultivos agrícolas; construcción de infraestructuras diversas, como presas; utilización de sistemas de irrigación inadecuados, e instalación de piscinas para acuicultura

El área del estudio de caracterización socioambiental comprendió un total de 28789118 hectáreas, incluyendo tanto el humedal de La Segua como su entorno ambiental más próximo. Con el análisis SIG y de imágenes de satélite (Figura 1) se pudieron determinar los cambios más significativos en los usos del suelo experimentados en las dos últimas décadas y confirmar los impactos ambientales detectados en el trabajo de campo y referidos en la Tabla 1 . En concreto, se pudo determinar una pérdida de un $35.9 \%$ de los cuerpos de agua, un proceso importante de deforestación que ha afectado a un total 3132.87 hectáreas de 


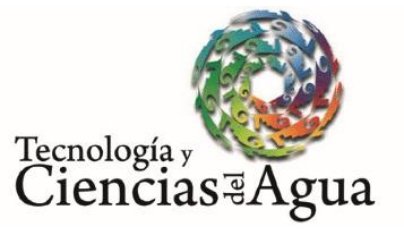

2021, Instituto Mexicano de Tecnología del Agua

Open Access bajo la licencia CC BY-NC-SA 4.0

(https://creativecommons.org/licenses/by-nc-sa/4.0/)

vegetación, lo que supone un porcentaje de pérdida de capa vegetal superior a tasa de deforestación media nacional estimada en un $0.11 \%$. Estos datos de deforestación pudieran parecer contradictorios con los resultados de los datos obtenidos sobre revegetación de un total de 3 508.73 hectáreas, pero ello tiene su explicación en la verificación de información realizada in situ, que registró la sustitución de la cobertura boscosa inicial por plantaciones de palmas inicialmente interpretadas como superficies de revegetación. El dato de inundación obtenido de 379 83 hectáreas representa el incremento de las áreas para uso acuícola (camaroneras) en zonas aledañas al humedal; mientras que la vegetación clara y densa inundable resulta de dos factores ambientales: el primero, de origen natural, derivado del cambio de cursos de cuerpos de aguas (ríos) o el surgimiento de nuevos cuerpos de aguas (ciénagas) como consecuencia de las lluvias, tal como se puede apreciar particularmente en el NE de la zona de estudio; y el segundo, de carácter antrópico, como resultado de la tala de cobertura boscosa para la creación de estanques artificiales para camaroneras, sobre todo en la zona NW del humedal.

Respecto a la percepción, actitudes y opiniones de la población (habitantes y agentes locales) sobre la situación ambiental y turística del territorio del humedal de La Segua, se aplicaron 50 encuestas in situ, que, en primer término, arrojaron resultados relativos positivos respecto al conocimiento y nivel de sensibilización ambiental sobre los valores ambientales, económicos y de generación de servicios ecosistémicos a la comunidad local de esta zona de estudio (un $69 \%$ de los encuestados manifestó conocer los valores del humedal; pero un $31 \%$ manifestó no saber sobre las actividades desarrolladas en el entorno del humedal y 


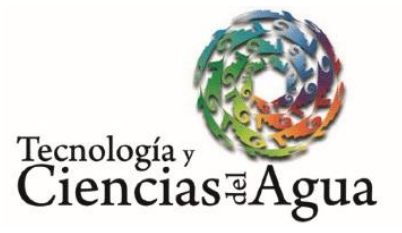

2021, Instituto Mexicano de Tecnología del Agua

Open Access bajo la licencia CC BY-NC-SA 4.0

(https://creativecommons.org/licenses/by-nc-sa/4.0/)

sobre sus impactos). En cualquier caso, se desprende la necesidad de fomentar los procesos de comunicación para informar y sensibilizar en mayor grado a la población local sobre la importancia que tiene este recurso territorial tanto en los ámbitos ecológico como económico, así como capacitarla a la hora de gestionar usos del suelo de manera más sostenible.

Los encuestados, en términos generales, son conscientes de las dinámicas más recientes que han ido provocando importantes cambios de usos del suelo en el entorno del humedal, así como de sus consecuencias: aparición de camaroneras; introducción de especies exóticas, como la tilapia (Oreochromis niloticus), que ha causado daños severos en especies endémicas como el chame (Dormitator latifrons), en la actualidad casi extinto; el inadecuado uso del suelo; la intensificación y malas prácticas de las actividades agrícolas, que cada vez más emplean productos agrotóxicos; y la expansión de las piscinas para la piscicultura.

Respecto a la percepción de la población local sobre la actividad turística y sus potencialidades en la zona, el $77 \%$ de los entrevistados reconoce la importancia del turismo para la diversificación de la economía tradicional del humedal, al mismo tiempo que expresa la necesidad de facilitar iniciativas favorecedoras del desarrollo turístico, como la planta alojativa, y los servicios complementarios de ocio y atención de visitantes tanto nacionales como internacionales. Por el contrario, el $23 \%$ de los encuestados desconocía el significado de la actividad turística y lo que pudiera representar para esta área, y dicho porcentaje manifiesta que la población local necesitaría antes que nada una buena capacitación y formación previas para entender realmente las posibilidades de esta 


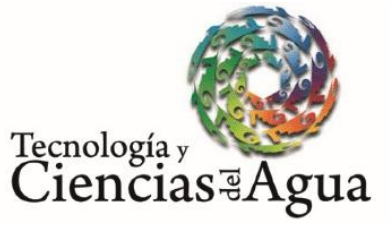

2021, Instituto Mexicano de Tecnología del Agua

Open Access bajo la licencia CC BY-NC-SA 4.0

(https://creativecommons.org/licenses/by-nc-sa/4.0/)

actividad para el desarrollo socioeconómico del entorno del humedal, y como oportunidad como nuevo yacimiento de empleo e iniciativas de emprendimiento.

El $61.84 \%$ de las personas asentadas en el entorno del humedal está de acuerdo, asimismo, con la promoción en la zona de actividades relacionadas con turismo, pues consideran que este territorio ganaría en visibilidad, notoriedad, atracción de inversiones y en generación de ingresos, parte de los cuales podrían revertir en una mejor conservación y ordenación de los recursos naturales del humedal. Por otra parte, un $32.89 \%$ no está de acuerdo con la irrupción de la actividad turística en la zona, al considerar que los réditos económicos no son redistribuidos de manera equitativa entre la comunidad local, concentrándose en muy pocos agentes u operadores económicos con intereses generalmente foráneos; $5.26 \%$ de encuestados se mantiene neutral, ya que considera que sus ingresos económicos no variarían ni dependerían en ningún caso de la actividad turística como tal.

Una vez hecho el diagnóstico socioambiental del humedal de La Segua, se presentan los resultados relativos a la aplicación de una matriz de indicadores de sostenibilidad respecto a variables como la conservación y gestión ambiental del espacio protegido; la gestión turístico-recreativa del mismom y sus potencialidades turísticas. Éstas se sintetizaron y clasificaron en la Tabla 2, Tabla 3, Tabla 4 y Tabla 5 . La matriz se clasificó, en concreto, en cuatro ámbitos de análisis (gestión general del espacio protegido, sostenibilidad ambiental, sostenibilidad sociocultural y sostenibilidad económica), y se estableció un sistema de indicadores ponderados en tres niveles: alto $(A)$, medio $(M)$ y bajo (B). 
Tabla 2. Indicadores de sostenibilidad en materia de gestión territorial integral del humedal y su entorno (alto, A; medio, M; bajo, B). Fuente: elaboración propia.

\begin{tabular}{|c|c|c|c|c|}
\hline Indicadores & $\mathbf{A}$ & $\mathbf{M}$ & B & Observaciones \\
\hline $\begin{array}{l}\text { Existencia de un plan } \\
\text { de manejo del } \\
\text { humedal con objetivos } \\
\text { de planificación } \\
\text { ambiental y turística }\end{array}$ & & & $x$ & $\begin{array}{l}\text { El plan de manejo que existe es del Ministerio } \\
\text { de Ambiente del año de } 2015 \text {, pero no hay } \\
\text { instrumentos sustantivos de desarrollo y } \\
\text { aplicación de éste. El municipio de Chone } \\
\text { realizó un estudio de los atractivos del } \\
\text { humedal, pero sin apenas orientación aplicada. } \\
\text { No se cumplen, en definitiva, las previsiones de } \\
\text { la planificación general }\end{array}$ \\
\hline $\begin{array}{l}\text { Existencia en la zona } \\
\text { de algún } \\
\text { departamento } \\
\text { administrativo de } \\
\text { gestión turística y } \\
\text { ambiental }\end{array}$ & & $\mathrm{X}$ & & $\begin{array}{l}\text { El área protegida, según el reparto de } \\
\text { competencias entre Administraciones Públicas } \\
\text { de Ecuador, debe ser gestionada por el } \\
\text { Gobierno Autónomo Descentralizado (GAD) del } \\
\text { cantón Chone-GAD parroquial y el GAD } \\
\text { provincial de Manabí }\end{array}$ \\
\hline $\begin{array}{l}\text { Presupuestos para el } \\
\text { manejo del área } \\
\text { protegida }\end{array}$ & & & $\mathrm{X}$ & $\begin{array}{l}\text { No existe un presupuesto establecido } \\
\text { especialmente para el manejo del área sino } \\
\text { solamente algunos recursos de inversión en } \\
\text { aspectos de infraestructuras y equipamientos } \\
\text { básicos de la población, o bien algunos } \\
\text { programas por parte de los GADS cantonales y } \\
\text { el GAD provincial }\end{array}$ \\
\hline $\begin{array}{l}\text { En qué medida se } \\
\text { reconocen y se } \\
\text { respetan los límites y }\end{array}$ & & $\mathrm{X}$ & & $\begin{array}{l}\text { Los límites son conocidos por parte de la } \\
\text { comunidad y gestores locales, y en menor } \\
\text { medida sus regulaciones de usos, pero }\end{array}$ \\
\hline
\end{tabular}


Ciencias $₫$ Agua

\begin{tabular}{|l|l|l|l|}
\hline $\begin{array}{l}\text { ordenanzas de la } \\
\text { zonificación para el } \\
\text { manejo y uso del } \\
\text { espacio protegido }\end{array}$ & & & $\begin{array}{l}\text { lamentablemente no se respetan y se } \\
\text { desarrollan numerosas actividades } \\
\text { descontroladas que atentan contra la } \\
\text { conservación e integridad ambiental del espacio } \\
\text { campañas de } \\
\text { promoción turística }\end{array}$ \\
$\begin{array}{l}\text { Extencia de } \\
\text { El área cuenta con } \\
\text { facilidades y } \\
\text { equipamientos para } \\
\text { satisfacer y atender la } \\
\text { demanda turístico- } \\
\text { recreativa }\end{array}$
\end{tabular}

Tabla 3. Indicadores de sostenibilidad en materia de gestión ambiental y de uso público (alto, A; medio, M; bajo, B). Fuente: elaboración propia.

\begin{tabular}{|c|c|c|c|c|}
\hline Indicadores & $\mathbf{A}$ & $\mathbf{M}$ & $\mathbf{B}$ & Observaciones \\
\hline $\begin{array}{l}\text { Existen operaciones } \\
\text { de control y vigilancia } \\
\text { ambiental }\end{array}$ & & & $x$ & $\begin{array}{l}\text { La contaminación del humedal derivada de las } \\
\text { actividades desarrolladas por los mismos } \\
\text { propietarios de tierras de este espacio es la } \\
\text { principal problemática ambiental, ya que suelen } \\
\text { utilizar sustancias contaminantes para el } \\
\text { mantenimiento de sus camaroneras, sin apenas } \\
\text { control de la inspección ambiental, que es } \\
\text { prácticamente inexistente }\end{array}$ \\
\hline
\end{tabular}


Ciencias $₫$ Agua

\begin{tabular}{|c|c|c|c|}
\hline $\begin{array}{l}\text { Calidad del agua del } \\
\text { humedal }\end{array}$ & & $x$ & $\begin{array}{l}\text { Mediante una investigación realizada por la } \\
\text { carrera ambiental de la ESPAM se ha podido } \\
\text { determinar un alto porcentaje de } \\
\text { contaminación de sus aguas por la actividad } \\
\text { pesquera y otra serie de factores secundarios }\end{array}$ \\
\hline $\begin{array}{l}\text { En qué nivel se } \\
\text { encuentra la } \\
\text { conservación del } \\
\text { paisaje del destino }\end{array}$ & $x$ & & $\begin{array}{l}\text { El entorno del humedal La Segua se encuentra } \\
\text { en un término medio de conservación, pues en } \\
\text { ciertos casos existe contaminación visual por el } \\
\text { crecimiento de camaroneras y actividades } \\
\text { agrícolas }\end{array}$ \\
\hline $\begin{array}{l}\text { Existencia de algún } \\
\text { programa de } \\
\text { actividades } \\
\text { permanentes de } \\
\text { educación e } \\
\text { información ambiental } \\
\text { para las comunidades } \\
\text { locales }\end{array}$ & & $x$ & $\begin{array}{l}\text { Las acciones de educación e información } \\
\text { ambiental no son permanentes y sólo se } \\
\text { organizan de manera muy esporádica y } \\
\text { puntual, coincidiendo con algunos días } \\
\text { conmemorativos (Día Mundial del Medio } \\
\text { Ambiente, Día Mundial de los Humedales) }\end{array}$ \\
\hline $\begin{array}{l}\text { El área protegida } \\
\text { dispone de } \\
\text { información } \\
\text { sistematizada para el } \\
\text { manejo del patrimonio } \\
\text { natural y cultural }\end{array}$ & & $x$ & $\begin{array}{l}\text { No existe un sistema de información } \\
\text { sistematizada, pero se pueden encontrar } \\
\text { algunos trabajos de investigación de } \\
\text { universidades, una guía de información } \\
\text { turística y el plan de manejo del área }\end{array}$ \\
\hline
\end{tabular}

Tabla 4. Indicadores de sostenibilidad sociocultural en el área de influencia del humedal (alto, A; medio, M; bajo, B). Fuente: elaboración propia.
Indicadores
\begin{tabular}{|l|l|l|}
$\mathbf{A}$ & $\mathbf{M}$ & $\mathbf{B}$ \\
\hline
\end{tabular}
Observaciones 


\begin{tabular}{|c|c|c|c|}
\hline $\begin{array}{l}\text { Nivel de aceptación y } \\
\text { conformidad de los } \\
\text { actores locales con } \\
\text { respecto a la } \\
\text { declaración oficial } \\
\text { como área protegida } \\
\text { de esta zona }\end{array}$ & $X$ & & $\begin{array}{l}\text { El grado de conocimiento sobre la importancia } \\
\text { de esta área protegida es de tipo medio, pero } \\
\text { existen muchos intereses económicos } \\
\text { cortoplacistas que permiten que se desarrollen } \\
\text { actividades que van en contra de la } \\
\text { conservación y sostenibilidad ambiental del } \\
\text { área protegida }\end{array}$ \\
\hline $\begin{array}{l}\text { Implementación de } \\
\text { programas para } \\
\text { mejorar el bienestar } \\
\text { de la comunidad local }\end{array}$ & & $X$ & $\begin{array}{l}\text { El presupuesto público para el manejo de esta } \\
\text { área es limitado, casi nulo; las acciones se } \\
\text { limitan a la organización de algunas actividades } \\
\text { de educación ambiental en las escuelas del } \\
\text { entorno }\end{array}$ \\
\hline $\begin{array}{l}\text { Participación de los } \\
\text { actores locales en la } \\
\text { toma de decisiones en } \\
\text { el manejo del área }\end{array}$ & & $X$ & $\begin{array}{l}\text { Prácticamente todo el territorio del humedal se } \\
\text { encuentra en terrenos de propiedad privada. } \\
\text { Sus propietarios realizan actividades } \\
\text { económicas diversas, principalmente pesqueras } \\
\text { y agrarias, pero la participación e implicación } \\
\text { en cuestiones relativas al manejo y } \\
\text { conservación ambiental del humedal es mínimo }\end{array}$ \\
\hline $\begin{array}{l}\text { En qué nivel se } \\
\text { conservan las } \\
\text { manifestaciones } \\
\text { culturales de la } \\
\text { comunidad }\end{array}$ & $X$ & & $\begin{array}{l}\text { Las manifestaciones culturales se preservan } \\
\text { especialmente en aspectos gastronómicos } \\
\text { (plato tradicional chame) y pesca artesanal }\end{array}$ \\
\hline
\end{tabular}

Tabla 5. Indicadores de sostenibilidad económica en el área de influencia del humedal (alto, A; medio, M; bajo, B). Elaboración propia.
Indicadores
\begin{tabular}{|l|l|l|}
$\mathbf{A}$ & $\mathbf{M}$ & $\mathbf{B}$ \\
\hline
\end{tabular}
Observaciones 


\begin{tabular}{|c|c|c|}
\hline $\begin{array}{l}\text { Los recursos naturales } \\
\text { del territorio generan } \\
\text { beneficios económicos } \\
\text { directos (ingresos, } \\
\text { empleos, turismo) a } \\
\text { las comunidades } \\
\text { locales }\end{array}$ & $x$ & $\begin{array}{l}\text { Los ingresos por actividades como turismo, } \\
\text { recreación, investigación o educación ambiental } \\
\text { son muy limitados y de escaso alcance, } \\
\text { mientras que sí tienen una incidencia } \\
\text { socioeconómica importante la agricultura, la } \\
\text { actividad pecuaria y la acuicultura, si bien la } \\
\text { óptica productivista a corto plazo de éstas se } \\
\text { desentiende de la necesaria sostenibilidad } \\
\text { ambiental }\end{array}$ \\
\hline $\begin{array}{l}\text { En qué medida se } \\
\text { benefician los actores } \\
\text { locales del turismo y } \\
\text { las actividades } \\
\text { recreativas que se } \\
\text { dan en la zona }\end{array}$ & $\bar{X}$ & $\begin{array}{l}\text { Una parte importante de la población local } \\
\text { parece percibir las potencialidades turístico- } \\
\text { recreativas del entorno del humedal, pero lo } \\
\text { cierto es que esta actividad tiene aún una } \\
\text { mínima participación y aportación en las } \\
\text { economías locales y, por tanto, la población no } \\
\text { percibe una generación de ingresos } \\
\text { procedentes del turismo realmente } \\
\text { significativa, sino muy minoritaria }\end{array}$ \\
\hline
\end{tabular}

El análisis externo del territorio del territorio del humedal se ha fundamentado en la aplicación de las encuestas para determinar la percepción y el perfil del visitante, además de saber cuáles son las necesidades y expectativas que éste pretende satisfacer en relación con los recursos territoriales y turístico-recreativos del humedal. Como síntesis de los resultados del estudio de la demanda podemos destacar lo siguiente:

1. Más del $50 \%$ de los visitantes son mayores de 35 años, muchos de ellos investigadores, extranjeros, ecologistas y ornitólogos que visitan 


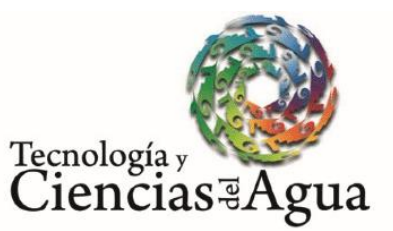

el lugar por motivo de estudios e investigación, siguiéndole otro $20 \%$ que corresponde a los estudiantes tanto de escuelas, colegios y universidades de la zona (visitas de educación ambiental). La mayoría son extranjeros y proceden de Europa (40 \%); en un segundo lugar, de Estados Unidos (40\%); y un bajo porcentaje son de origen nacional $(20 \%)$, lo que evidencia el poco interés de los visitantes locales y nacionales por estos espacios protegidos, y la escasa promoción turística para captar tal demanda por parte de las administraciones competentes.

2. El $46 \%$ de los visitantes tiene formación universitaria, con empleo estable, y con disposición a pagar 86 dólares/día por los productos y servicios turístico-recreativos que puedan planificarse en la zona.

3. La mayoría viaja en familia y con amigos (un $44 \%$ ), siendo éste un factor positivo por su mayor nivel de gasto final.

4. El $60 \%$ de los encuestados conoce o ha escuchado hablar del humedal, pero reconoce que existe una deficiente promoción que no permite difundir de modo conveniente sus valores naturalísticos, paisajísticos y turístico-recreativos. La mayoría de los encuestados manifiesta que tuvo acceso a información sobre el humedal a través de las redes sociales, páginas web especializadas y comentarios de amigos y conocidos, pero no por medio de canales de promoción turística.

5. La principal motivación de la visita es conocer y disfrutar de la biodiversidad y los recursos naturales, y a pesar de no existir una oferta de servicios de atención al visitante propiamente dicha, manifiestan tener una buena percepción del espacio protegido.

6. Finalmente, entre las deficiencias que encuentran en el humedal, señalan en particular la práctica inexistencia de productos turísticos 


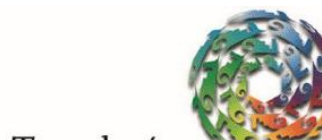

Tecnología y

Ciencias $\approx$ Agua
2021, Instituto Mexicano de Tecnología del Agua

Open Access bajo la licencia CC BY-NC-SA 4.0

(https://creativecommons.org/licenses/by-nc-sa/4.0/)

especializados de ecoturismo, turismo ornitológico o de educación ambiental, así como de guías bilingües; la falta de equipamientos e infraestructuras de uso público; y la escasez de servicios turísticos en la zona de influencia del área protegida.

Partiendo de los resultados del diagnóstico socioambiental y de las opiniones y sugerencias de los agentes locales encuestados, y de las realizadas a visitantes, hemos concretado una serie de propuestas de acciones y estrategias de planificación que aborden las problemáticas detectadas en el espacio natural tanto desde el punto de vista ambiental como turístico-recreativo y de desarrollo sostenible. Estas propuestas se reflejan en la matriz de la Tabla 6 y entendemos que deberían ser articuladas en el marco de un plan de acción más integral y de perspectivas más amplias que el actual Plan de Manejo del Humedal, que ni tan siquiera se ha desarrollado hasta el momento a través de acciones sustantivas.

Tabla 6. Matriz de acciones y estrategias propuestas turístico-recreativo para el humedal La Segua. Fuente: elaboración propia.

\begin{tabular}{|c|c|c|c|}
\hline Problemas & $\begin{array}{l}\text { Objetivos } \\
\text { generales }\end{array}$ & Proyectos & Estrategias \\
\hline $\begin{array}{l}\text { Falta de personal } \\
\text { cualificado en } \\
\text { gestión turística } \\
\text { y del uso público } \\
\text { Deficiencias de } \\
\text { gestión pública }\end{array}$ & $\begin{array}{l}\text { Fomento de la } \\
\text { actividad } \\
\text { turístico- } \\
\text { recreativa bajo } \\
\text { criterios de } \\
\text { sostenibilidad, } \\
\text { fomentando la }\end{array}$ & $\begin{array}{l}\text { Herramientas y } \\
\text { talleres de } \\
\text { involucramiento } \\
\text { de principales } \\
\text { actores y gestores } \\
\text { locales } \\
\text { cualificados para }\end{array}$ & $\begin{array}{l}\text { Coordinación } \\
\text { interadministrativa entre } \\
\text { AAPP ambientales y } \\
\text { turísticas, y creación de } \\
\text { un organismo consultivo } \\
\text { para promover la } \\
\text { participación social en la }\end{array}$ \\
\hline
\end{tabular}


Ciencias $\approx$ Agua

\begin{tabular}{|c|c|c|c|}
\hline $\begin{array}{l}\text { ambiental y } \\
\text { turística }\end{array}$ & $\begin{array}{l}\text { pluriactividad } \\
\text { económica y el } \\
\text { desarrollo } \\
\text { sostenible con } \\
\text { base } \\
\text { comunitaria, } \\
\text { para mejora de } \\
\text { la calidad de } \\
\text { vida de la } \\
\text { población del } \\
\text { entorno }\end{array}$ & $\begin{array}{l}\text { compensar déficit } \\
\text { de personal } \\
\text { técnico } \\
\text { La obtención de } \\
\text { ingresos por } \\
\text { entrada de } \\
\text { visitantes debería } \\
\text { retornar en la } \\
\text { mejora de la } \\
\text { logística de } \\
\text { gestión ambiental } \\
\text { y turístico- } \\
\text { recreativa del } \\
\text { humedal }\end{array}$ & $\begin{array}{l}\text { Identificar proyectos } \\
\text { innovadores de carácter } \\
\text { mixto (conservación + } \\
\text { desarrollo), que enfoquen } \\
\text { de manera sostenible la } \\
\text { puesta en valor de los } \\
\text { recursos territoriales con } \\
\text { mayor potencialidad } \\
\text { Actualización del Plan de } \\
\text { Manejo de } 2015 \text { y } \\
\text { equiparación con demás } \\
\text { áreas del Sistema } \\
\text { Nacional de Áreas } \\
\text { Protegidas del Estado, } \\
\text { con un sistema de } \\
\text { financiación } \\
\text { autosuficiente para la } \\
\text { gestión integral del } \\
\text { humedal. Mejora de los } \\
\text { servicios públicos de } \\
\text { evacuación y depuración } \\
\text { de aguas residuales }\end{array}$ \\
\hline $\begin{array}{l}\text { Descontrol en las } \\
\text { expansiones de } \\
\text { terrenos para } \\
\text { camaroneras y } \\
\text { prácticas } \\
\text { agrarias poco }\end{array}$ & $\begin{array}{l}\text { Fomentar } \\
\text { estrategias } \\
\text { sostenibles que } \\
\text { admitan la } \\
\text { conservación y } \\
\text { el uso racional }\end{array}$ & $\begin{array}{l}\text { Educación } \\
\text { ambiental }\end{array}$ & $\begin{array}{l}\text { Capacitación de la } \\
\text { población local en } \\
\text { prácticas agrarias y } \\
\text { pesqueras sostenibles, y } \\
\text { proyectos alternativos de } \\
\text { producción ecológica }\end{array}$ \\
\hline
\end{tabular}


Ciencias $₫$ Agua

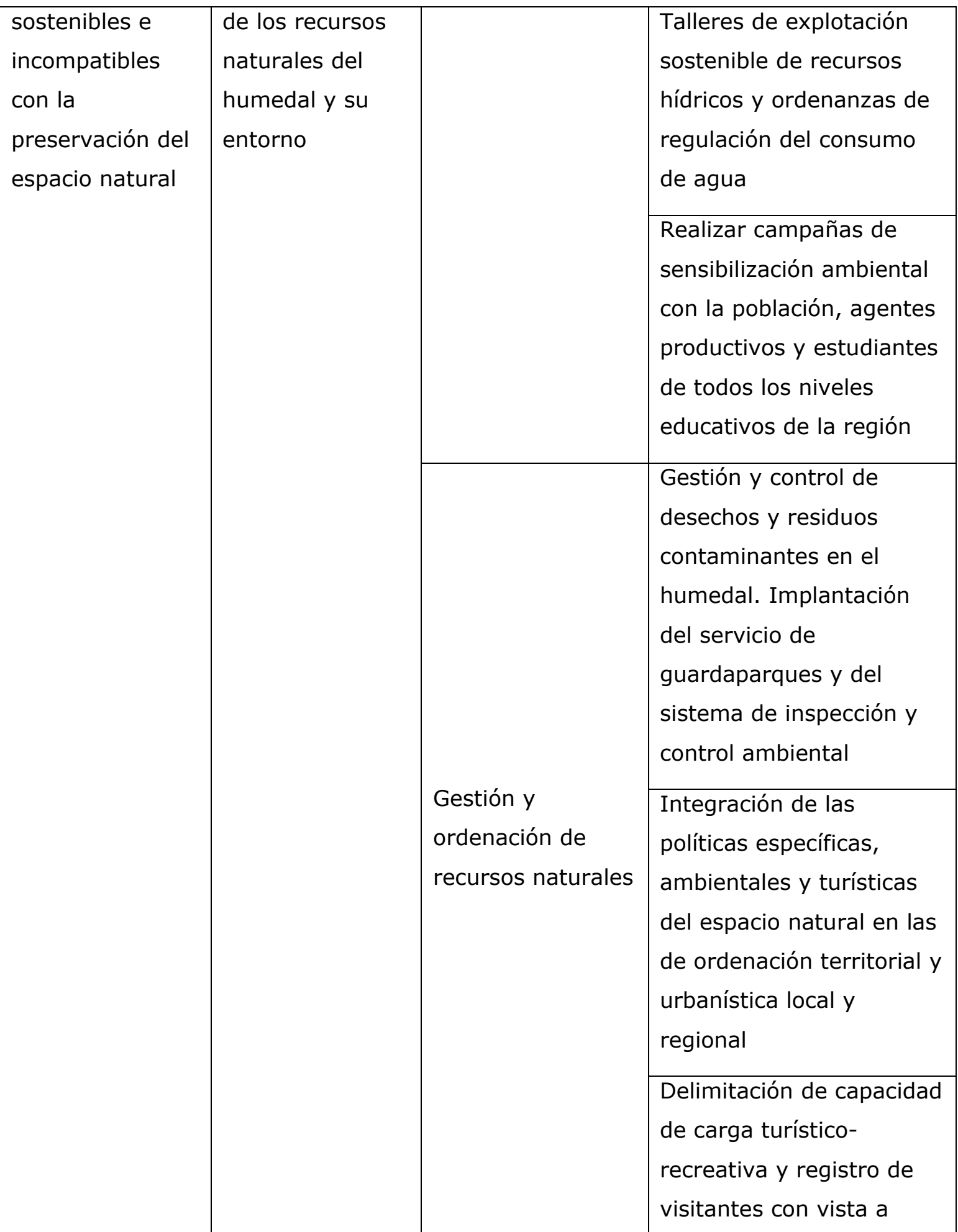




\begin{tabular}{|c|c|c|c|}
\hline & & & $\begin{array}{l}\text { fortalecer la planificación } \\
\text { del humedal (desarrollo } \\
\text { del Plan de Manejo con } \\
\text { un Plan de Ordenación de } \\
\text { Recursos Naturales, un } \\
\text { Plan Rector de Uso y } \\
\text { Gestión con órganos } \\
\text { sustantivos de decisión, y } \\
\text { un Plan de Desarrollo } \\
\text { Sostenible }\end{array}$ \\
\hline $\begin{array}{l}\text { Infraestructura y } \\
\text { equipamientos } \\
\text { turísticos } \\
\text { insuficientes o } \\
\text { deficientes } \\
\text { Pérdidas de } \\
\text { turistas por } \\
\text { escasez de } \\
\text { equipamientos y } \\
\text { servicios } \\
\text { turísticos de } \\
\text { acogida. Turismo } \\
\text { internacional } \\
\text { sólo ligado al } \\
\text { turismo científico } \\
\text { y educativo. } \\
\text { Turismo nacional } \\
\text { y de proximidad } \\
\text { escaso. Poca } \\
\text { generación de } \\
\text { ingresos por }\end{array}$ & $\begin{array}{l}\text { Impulsar la } \\
\text { economía de las } \\
\text { comunidades } \\
\text { asentadas en los } \\
\text { alrededores de } \\
\text { los humedales a } \\
\text { través del } \\
\text { desarrollo y } \\
\text { difusión de } \\
\text { productos } \\
\text { turístico- } \\
\text { recreativos que } \\
\text { permitan el } \\
\text { aprovechamiento } \\
\text { óptimo de los } \\
\text { recursos }\end{array}$ & $\begin{array}{l}\text { Fomento de } \\
\text { proyectos de } \\
\text { turismo } \\
\text { comunitario desde } \\
\text { iniciativas público- } \\
\text { privadas con } \\
\text { participación } \\
\text { activa de agentes } \\
\text { locales. } \\
\text { Potenciación de } \\
\text { segmentos de } \\
\text { demanda de } \\
\text { ecoturismo, } \\
\text { turismo } \\
\text { ornitológico, } \\
\text { turismo de } \\
\text { educativo- } \\
\text { ambiental y } \\
\text { agroturismo, } \\
\text { mediante técnicas } \\
\text { de benchmarking }\end{array}$ & $\begin{array}{l}\text { Planes de capacitación y } \\
\text { formación de recursos } \\
\text { humanos en gestión } \\
\text { turística. Líneas de } \\
\text { fomento para creación de } \\
\text { productos turísticos } \\
\text { demostrativos e } \\
\text { innovadores } \\
\text { Campañas de promoción } \\
\text { turística, sobre todo en } \\
\text { marketing digital, para } \\
\text { atracción del turismo } \\
\text { nacional y de proximidad, } \\
\text { y el turismo internacional } \\
\text { convencional de turismo } \\
\text { de naturaleza. Plan de } \\
\text { turismo ornitológico }\end{array}$ \\
\hline
\end{tabular}


Ciencias $₫$ Agua

\begin{tabular}{|l|l|l|l|}
\hline turismo, apenas & y posible & de clusters turísticos \\
percibidos por la & traslación de & público-privados \\
población local & buenas prácticas & \\
& & de otros espacios & \\
& protegidos & \\
& similares & \\
\hline
\end{tabular}

\section{Discusión}

Para la gestión de los flujos turístico-recreativos en los espacios protegidos, su planificación medioambiental y el impulso del desarrollo local, la caracterización socioambiental del territorio y de los visitantes se revela como una necesidad básica. Cuando no cuentan con ésta, como es en el caso del humedal de La Segua aquí estudiado, la planificación turística y medioambiental presenta notables deficiencias, y los recursos patrimoniales y equipamientos de uso público son insuficientes, inadecuados o suelen encontrarse infrautilizados, y con problemas de funcionalidad y sostenibilidad, además de no responder a las expectativas de la demanda de los visitantes. El turismo de naturaleza se puede convertir en una herramienta fundamental para el desarrollo socioeconómico de las poblaciones situadas en el área de influencia de los humedales y aliviar las condiciones de pobreza que suelen sufrir sus poblaciones rurales, pero para ello es necesaria una planificación y una 


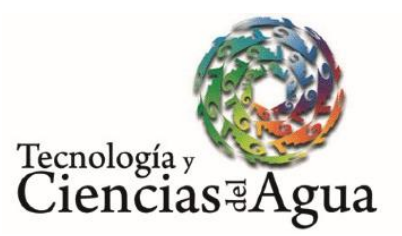

gestión pública adecuadas desde el punto de vista medioambiental y turístico (Fisher, Maginnis, Jackson, Barrow, \& Jeanrenaud, 2005; Vander-Duim \& Henkens, 2007; Vera \& Marchena, 2014; Mulero \& Rivera, 2018), lo que ciertamente no es fácil de aplicar, sobre todo en territorios como el que aquí estudiamos, donde carecemos de estudios y evaluaciones previas sobre demanda y frecuentación turístico-recreativa; comportamiento de los flujos de visitantes; impactos ambientales, socioeconómicos y culturales previsibles; y niveles de adecuación y funcionalidad de los equipamientos de uso público. Los estudios de caso como el que aquí acometemos se hacen, en este sentido, muy necesarios, teniendo en cuenta la heterogeneidad de situaciones y casuísticas que pueden encontrarse en los humedales de Ecuador (Secretaría de la Convención Ramsar, 2012; Molina, 2012).

Pese a estar incluido el humedal de La Segua en el Sistema Nacional de Áreas Protegidas del Estado y tener aprobado el Plan de Manejo de 2015 como área protegida provincial, lo cierto es que hasta la fecha se han dado pocos avances efectivos y sustantivos en materia de conservación y gestión ambiental y territorial de esta zona, y aun cuando cabe recalcar que forma parte del patrimonio natural del país y ostenta el título internacional de humedal Ramsar, ubicado en el puesto número cinco en la lista nacional de Ecuador (Molina, 2012), los resultados obtenidos de las encuestas, trabajo de campo y observación directa confirman el fuerte déficit existente en materia de gestión y gobernanza ambiental, y mucho más desde el punto de vista turístico-recreativo y de uso público. 


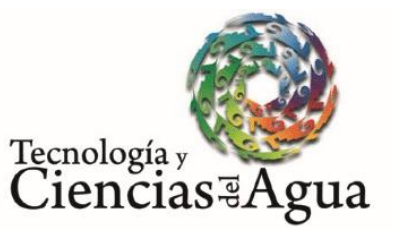

Hay que considerar, en este sentido, que la administración y gestión ambiental de este espacio es competencia tanto del Gobierno Provincial de Manabí como del municipio del cantón Chone, pese a lo cual no existe una unidad administrativa especializada para la gestión y el manejo del humedal; además, la coordinación interadministrativa entre ambos organismos, y entre éstos y el Ministerio del Ambiente es muy deficiente y desestructurada. El Plan de Manejo de 2015 sólo aborda una ordenación muy general de los recursos naturales del humedal y su entorno, pero no cuenta con un desarrollo reglamentario para concretar acciones rectoras, de uso público y gestión de los suelos, así como de zonificación operativa. Y es precisamente el manejo de los suelos el que centra la problemática actual del territorio, pues prácticamente toda la zona es de propiedad privada y sufre un nivel relativamente importante de intensificación creciente de actividades productivas primarias (agropecuarias y piscicultura), sin existir ninguna zona de protección y amortiguación de impactos en la zona de influencia perimetral del humedal, así como tampoco, en la práctica, de una declaración con vinculación jurídica suficiente como área protegida de ámbito estatal que pudiera reforzar las condiciones de protección y sostenibilidad ambiental de ese espacio.

El humedal de La Segua, como otros sitios Ramsar de características similares, es una zona geográfica con un gran potencial de diversidad biológica, ideal para investigaciones y actividades de educación ambiental y ecoturismo, en especial en la rama del aviturismo o turismo ornitológico. No obstante, la gestión pública de este espacio protegido se centra básicamente en la vertiente ambiental y de conservación de la naturaleza y, por añadidura, al no estar reconocido dentro del Subsistema de 
Tecnología y

Patrimonio de Áreas Naturales del Estado, este humedal recibe menos recursos que otros sitios Ramsar del país, y no puede beneficiarse de algunos proyectos coordinados de conservación ambiental y turismo sostenible entre los Ministerios del Ambiente y Turismo (Torres, 2012; Molina, 2012).

Nos encontramos, por tanto, con un espacio protegido que apenas está siendo aprovechado desde el punto de vista turístico-recreativo, a pesar de que el Plan del "Buen Vivir" del gobierno de Ecuador (República del Ecuador, 2017) contempla al ecoturismo como un subsector estratégico de actividad económica para la generación de empleo, y riqueza de manera sostenible y compatible con la conservación de la naturaleza. En realidad, pese a las potencialidades turístico-recreativas que hemos podido identificar en el humedal y su entorno geográfico, su declaración como área protegida no ha sido con la finalidad expresa de estimular estrategias de desarrollo sostenible, entre ellas la actividad turístico-recreativa, sino que ha respondido exclusivamente a su preservación ecológica y paisajística, como se desprende del Plan de Manejo de 2015, y como ha ocurrido en otros humedales de Ecuador e incluso en no pocos países con instrumentos más avanzados de ordenación territorial y fomento económico (Papayannis, 2002; AriasGarcía \& Gómez-Zotano, 2015); todo esto ha provocado que resulte difícil determinar su verdadera concepción como instrumento de ecodesarrollo y revulsivo socioeconómico para las áreas deprimidas de su entorno.

No cabe duda de que la orientación a nivel de gestión de este espacio va en dirección un tanto opuesta a las determinaciones y recomendaciones del propio Convenio Ramsar, que ha supuesto un 


\section{Tecnología y 4 करते \\ Ciencias $\stackrel{\unlhd}{\triangle}$ Agua}

2021, Instituto Mexicano de Tecnología del Agua

Open Access bajo la licencia CC BY-NC-SA 4.0

(https://creativecommons.org/licenses/by-nc-sa/4.0/)

importante punto de partida para los numerosos instrumentos, planes y estrategias que en los últimos años han tratado de garantizar la conservación y revalorización de los humedales (Iza, 2004; Serrano, 2012). Por ello, además de identificar, sistematizar y analizar las distintas medidas puestas en marcha hasta la fecha en el humedal, hemos obtenido del trabajo de campo y los contactos con agentes locales, visitantes y expertos una serie de propuestas que puedan mejorar la gestión de esta zona húmeda, una vez que hemos comprobado que las actuaciones derivadas de la planificación ambiental resultan insuficientes y dificultan la gestión integral de este ecosistema, que habría de conexionar y compatibilizar la orientación ambiental con la turístico-recreativa y de desarrollo sostenible.

A pesar de la gran importancia de este sitio Ramsar para el patrimonio natural del país, resulta evidente que la población local, los agentes socioeconómicos, y hasta las instituciones públicas y privadas implicadas no son suficientemente conscientes de la importancia de este lugar como prestador de servicios ecosistémicos de valor, incluidos los turístico-recreativos, que pueden generar nuevas oportunidades de desarrollo complementarios a las actividades primarias tradicionales. Por tanto, las potencialidades turístico-recreativas del humedal sólo pueden desarrollarse mediante un proceso de sensibilización, información y capacitación previas de estos agentes locales, así como con la implementación de un Plan de Ordenación y Gestión que supere la vertiente exclusivamente ambiental del actual Plan de Manejo de 2015, y contenga determinaciones para la ordenación de los recursos territoriales turísticos y su capacidad de carga turístico-recreativa, teniendo en cuenta 


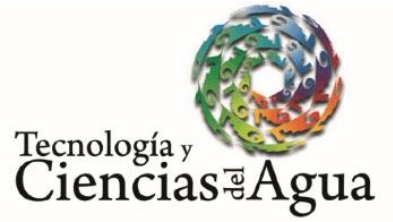

la fragilidad medioambiental del humedal y la afluencia futura de visitantes que pueden llegar a este destino en cuanto se pongan en valor equipamientos e infraestructuras de acogida suficientes y adecuados, y se realicen acciones de promoción y comercialización, ahora prácticamente inexistentes.

En los últimos años es verdad que se han habilitado algunos equipamientos de uso público de orientación turística-recreativa y de educación ambiental, destacando la presencia de un centro de visitantes del humedal, en el que tiene su sede la Asociación Ecoturística de Guías Naturalistas del Humedal La Segua (Asohumedal), con una trayectoria de más de una década operando en la zona, junto con la Asociación de Producción Pesquera Artesanal Humedal La Segua (Asoprosegua). Ambas han recibido algún apoyo del Gobierno Provincial de Manabí y cuentan con la colaboración puntual de la Alcaldía de Chone. Pero lo cierto es que la oferta todavía embrionaria de actividades turístico-recreativas en la zona apenas tienen conexión y sinergias favorables con las administraciones ambientales competentes y sus estrategias generales de actuación, y no cuenta, además, con un sistema de apoyo a nivel promocional y de comercialización del Ministerio de Turismo de Ecuador, que sea adecuado para este tipo de espacios protegidos.

Este Ministerio, $y$ otras entidades y ONG nacionales $e$ internacionales han puesto en marcha algunos equipamientos de uso público en el entorno del humedal, pero sin implicación y colaboración interadministrativa del Ministerio de Ambiente de Ecuador, y sin ningún soporte efectivo y estructurado de promoción y comercialización, por lo que las iniciativas siempre han sido un tanto escasas, puntuales y 


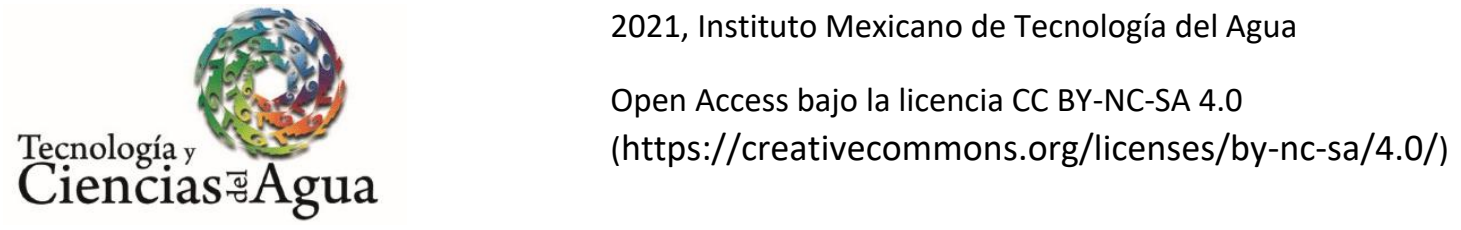

descoordinadas, sin siquiera evaluación previa de impactos. En el paisaje acuático del humedal, tan sólo desde 2010 se han puesto en marcha algunas iniciativas novedosas en cuanto a equipamientos, pero han resultado ser insuficientes para afianzar este espacio protegido como el principal destino de naturaleza de Manabí, pese a sus potencialidades reales para serlo. Nos referimos, en este sentido, al sendero Los Caimanes, que incluye una pasarela de madera sobre las aguas y una torre que funciona como mirador para disfrutar de uno de los grandes atractivos del lugar: la ornitología y la avifauna (Figura 3). Estos trabajos fueron financiados por la Agencia de los Estados Unidos para el Desarrollo Internacional (USAID), con la colaboración del municipio de Chone, que aportó maquinaria para rellenar el sendero, así como del Ministerio de Turismo, que construyó el mirador actualmente existente. Existe, asimismo, un muelle con canoas y chalecos salvavidas, donde se organizan algunas actividades; pero la oferta de servicios en las zonas aledañas es muy limitada; se cuenta con pequeños restaurantes y casas de comida, pero sin ningún establecimiento de hospedaje. 

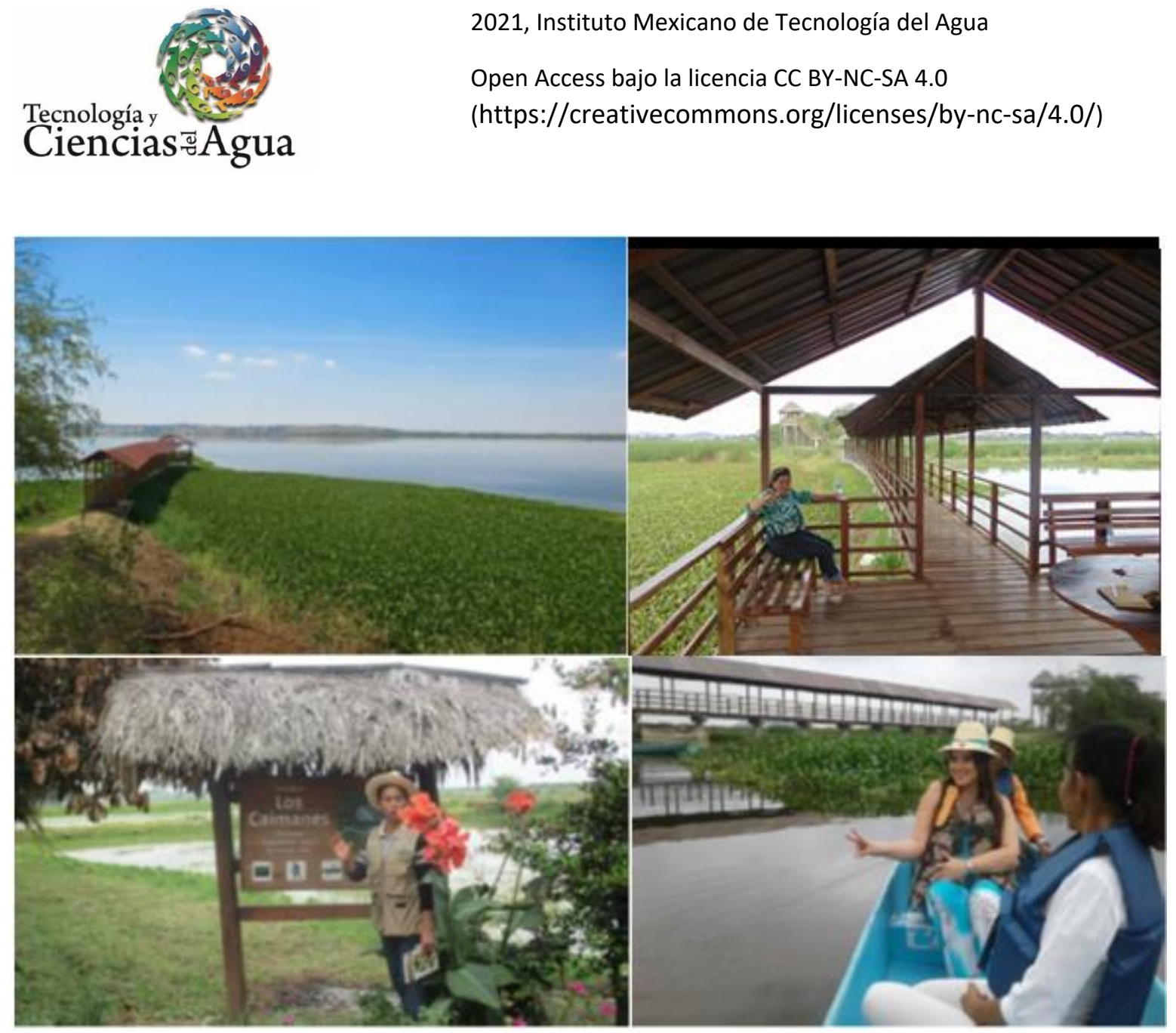

Figura 3. Humedal La Segua. Fuente: elaboración propia.

Los recursos naturales del entorno del humedal, su rica biodiversidad y los valores singulares del paisaje, así como el atractivo de la observación de aves residentes y migratorias, constituyen una base importante para el desarrollo de actividades turístico-recreativas, al igual que los recursos socioculturales, como la gastronomía tradicional, que tiene aquí al chame, la tilapia y el camarón como sus principales componentes. No obstante, la inexistencia de estrategias creativas a nivel de diseño de productos, promoción y comercialización, y creación de equipamientos y servicios turísticos complementarios está haciendo que la actividad turística apenas genere ingresos y flujos de visitantes 


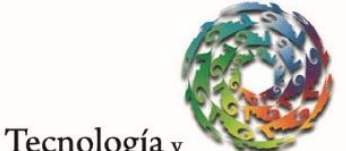 \\ Ciencias $\stackrel{\unlhd}{\triangle}$ Agua}

2021, Instituto Mexicano de Tecnología del Agua

Open Access bajo la licencia CC BY-NC-SA 4.0

(https://creativecommons.org/licenses/by-nc-sa/4.0/)

destacables en la zona, y que la propia población local no perciba, al menos a corto plazo, a esta actividad como un instrumento real de desarrollo socioeconómico, a diferencia de otras actividades, como la agricultura, ganadería y acuicultura, pese a los mayores impactos ambientales que éstas generan en el territorio, y sus prácticas tradicionales de escasos niveles de sostenibilidad (Mulero \& Rivera, 2018).

Las iniciativas turístico-recreativas y de desarrollo sostenible en espacios naturales como éste, tal como aconsejan diversos organismos internacionales y ONG experimentados en estudios de caso (Font, Cochrane, \& Tapper, 2004; OMT, 2004; Van-der-Duim \& Henkens, 2007), han de emplear técnicas de participación público-privada y herramientas de planificación -ahora inexistentes en la gestión del humedal- que lidien con posibles conflictos de intereses entre propietarios privados y otros agentes de actividades económicas, y los involucren en el desarrollo de proyectos de turismo sostenible y comunitario. El análisis de dichas técnicas y herramientas va más allá del alcance de esta publicación, como podrá entenderse, pero podemos afirmar que la clave para planificar, acertada y eficazmente, el desarrollo turístico sostenible en los humedales es integrando aspectos técnicos en el proceso de planificación (p. ej., la administración de recursos y visitantes; la ordenación de recursos naturales; y el desarrollo y la comercialización de productos) con la participación pública de todos los grupos interesados.

En consecuencia, si los procesos que tienen múltiples actores y grupos de interés como los que hemos observado en La Segua buscan ser 


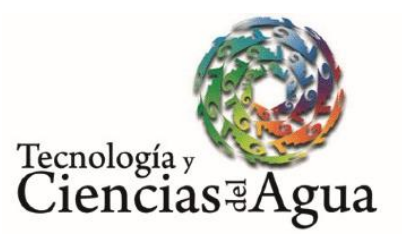

equilibrados, legítimos y abiertos deben satisfacer por lo menos algunos de los siguientes criterios (Steck, 1999; SNV, 2001):

1. Los diferentes actores deben involucrarse desde el inicio, aceptar el proceso y su propósito, y "apropiarse" del proceso de desarrollo turístico sostenible.

2. Todos los grupos interesados deben estar representados y se debe exigir participación activa a los representantes de cada organización o grupo (hemos propuesto una Junta o Consejo Rector del espacio protegido a nivel consultivo de las administraciones gestoras).

3. Todos los actores y grupos interesados deben tener igual acceso a la información, los recursos y la experiencia.

4. La forma en que se toman las decisiones y el grado de influencia que tendrán los participantes debe ser clara y transparente.

\section{Conclusiones}

La caracterización socioambiental del entorno del humedal de La Segua nos ha permitido identificar diversos problemas ambientales, como la degradación y pérdida acelerada de hábitats por presiones antrópicas; la tendencia a la desecación y reducción de espejos de agua; el uso inadecuado de los recursos hídricos superficiales por ampliación de la 


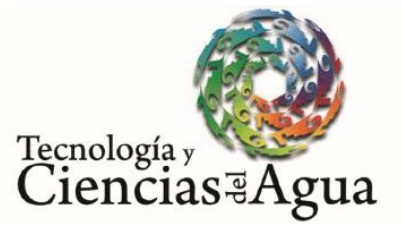

2021, Instituto Mexicano de Tecnología del Agua

Open Access bajo la licencia CC BY-NC-SA 4.0

(https://creativecommons.org/licenses/by-nc-sa/4.0/)

frontera agrícola; la construcción de infraestructuras carentes en todos los casos de evaluación previa de impacto ambiental; y la introducción de especies exóticas, con los consecuentes daños generados en especies endémicas, entre otras cuestiones.

La sobrepoblación de piscinas acuícolas para el cultivo de camarón, y las grandes áreas para la ganadería y diversos monocultivos agrícolas saltan a la vista, sin que las autoridades locales, provinciales o estatales planteen estrategias de planificación territorial para una gestión integral adecuada de este espacio de suma fragilidad ambiental; a esto se suma el relativo desinterés de los actores locales por su implantación, en la medida en que puedan limitar o condicionar sus aprovechamientos económicos tradicionales, además de por la mínima participación que se les permite en las acciones desarrolladas por las administraciones públicas.

Por otra parte, con esta caracterización socioambiental y el perfil de visitantes analizado, se puede comprender la compleja relación entre el manejo ambiental del humedal, la reducción de la pobreza en el entorno rural y el desarrollo de las potencialidades que tiene la zona para el turismo sostenible. Es evidente que deben mirarse con cautela las oportunidades de desarrollar el turismo, pero éste tiene notables posibilidades si las organizaciones y autoridades implicadas en el humedal son capaces de instrumentar y consensuar con la población local planes de gestión realistas que reconozcan dicho potencial, aunque sin sobreestimar sus beneficios socioeconómicos, ni subestimar sus costes ambientales y socioculturales. 


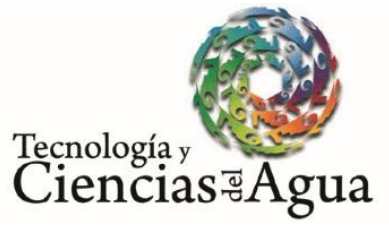

La aproximación que se realiza en este trabajo a la caracterización de este espacio natural protegido intenta orientar por ello sus políticas territoriales y sectoriales con incidencia en el turismo de naturaleza, y su necesaria compatibilización con la conservación del patrimonio natural que le sirve de soporte y cualificación. Esto, si cabe, es especialmente importante en un espacio protegido, en el que la principal motivación de los visitantes está relacionada con el disfrute de la biodiversidad, el paisaje y los recursos naturales de la zona. La percepción de estos visitantes sobre los valores y atractivos del humedal es positiva en términos generales, pero no se ve compensada de manera suficiente como para alcanzar importantes niveles de satisfacción y una estancia media de más de un día, ya que no existe una oferta de servicios turísticos y de ocio suficiente y mínimamente estructurada. De hecho, entre las necesidades manifestadas por los visitantes, se subraya la existencia de productos turísticos especializados, guías bilingües, y mejoras sustanciales en la infraestructura de soporte y los servicios turísticos de alojamiento y restauración de cierta calidad. El predominio de visitantes de proximidad y excursionistas en la zona, y la escasa presencia del turismo internacional genérico habla por sí solo de un desarrollo turísticorecreativo muy embrionario y deficiente; de escasa repercusión socioeconómica en las comunidades locales aledañas. Así una parte importante de la población local no percibe la actividad turística como un motor de desarrollo significativo al menos a corto y mediano plazos.

Este estudio ha intentado obtener algunas lecciones aprendidas que sirvan de orientación para la puesta en marcha de futuros proyectos ecoturísticos en la zona, y algunas otras actividades turístico-recreativas 


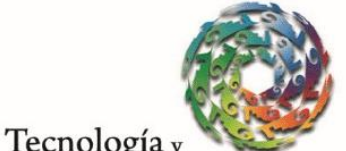 \\ Ciencias $\stackrel{\unlhd}{\triangle}$ Agua}

2021, Instituto Mexicano de Tecnología del Agua

Open Access bajo la licencia CC BY-NC-SA 4.0

(https://creativecommons.org/licenses/by-nc-sa/4.0/)

que permitan obtener ingresos complementarios a los de las actividades agrarias y pesqueras tradicionales, asumiendo que este tipo de actividades blandas en la naturaleza relacionadas con el turismo pueden compatibilizarse con la conservación y protección ambiental del humedal y la biodiversidad de su entorno, así como con la propia sustentabilidad de la región y sus comunidades locales (turismo científico, educación ambiental, investigación, emprendimientos de ecoturismo y turismo comunitario). Pero para ello debe existir en este espacio protegido una estrategia turística bien definida, que ha de partir de la capacitación y formación profesional de los agentes locales en el diseño, la creación, promoción y la comercialización de productos turístico-recreativos que, a su vez, sigan criterios de sostenibilidad ambiental de acuerdo con las directrices del Plan de Manejo del Humedal de 2015 que, en cualquier caso, habría de desarrollarse y concretarse en unas ordenanzas reguladoras y zonificadas más sustantivas, y en un Plan Rector de Uso y Gestión Integral de dicha área protegida.

En definitiva, entendemos que es necesario revisar el papel que han de desempeñar las administraciones competentes en estos espacios protegidos; pero, al mismo tiempo, de importantes potencialidades turístico-recreativas como este humedal de La Segua. Hemos visto cómo las carencias son aún considerables en la articulación de iniciativas de gestión y planificación; la falta de criterios adecuados para la ordenación de los usos y aprovechamientos del suelo; y la necesaria renovación, reconceptualización y adaptación de la estrategia turística nacional sobre desarrollo turístico a la casuística específica de estos humedales. No se ha de olvidar, en este sentido, que el turismo es una actividad muy 


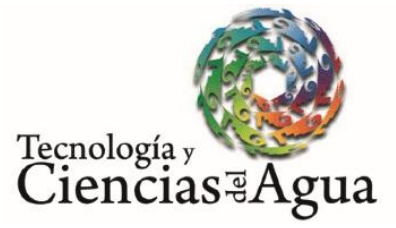

2021, Instituto Mexicano de Tecnología del Agua

Open Access bajo la licencia CC BY-NC-SA 4.0

(https://creativecommons.org/licenses/by-nc-sa/4.0/)

transversal que, de manera especial en este caso de estudio, ha de desarrollarse en un ámbito protegido de gran fragilidad ambiental, por lo que se requiere de una coordinación eficaz entre las diferentes administraciones implicadas, y entre éstas y todos los agentes y la población local intervinientes en el desarrollo turístico (Mulero \& Rivera, 2018).

Para plantear, en fin, acciones que fundamenten el desarrollo turístico de La Segua han de considerarse los resultados y lecciones aprendidas de otros casos donde se han aplicado algunas buenas prácticas y que resulten compatibles con el establecimiento de proyectos de turismo comunitario en el marco de una gestión sostenible e integral de este espacio (Idelhadj, Rivera-Mateos, \& Rodríguez-García, 2012), buscando algunas soluciones para las principales necesidades de la población, con la prestación de servicios de calidad para los visitantes, y el aprovechamiento racional y ordenado de los recursos naturales y culturales del territorio. La propuesta final expresada en este trabajo se ha estructurado por último en cuatro proyectos y 11 estrategias, que buscan una ordenación territorial integral de este espacio protegido, su lanzamiento como destino de turismo comunitario de naturaleza y el fortalecimiento de la gestión pública ambiental y turística, creando mecanismos de vinculación y participación con los actores locales.

\section{Referencias}

Alatorre, A., \& Pérez, M. (2011). Procedimiento para medir la demanda turística en un destino. Revista de Investigación en Turismo y Desarrollo Local TURyDES, 4(11), 1-25. 
Tecnología y

Arias-García, J., \& Gómez-Zotano, J. (2015). La planificación y gestión de los humedales de Andalucía en el marco del Convenio Ramsar. Investigaciones Geográficas, 63, 117-129.

Cardozo, P., Fernández, D., Soares, J., \& Holm, C. (2016). Cooperación y participación en el proceso de planificación y desarrollo turístico. Estudios y Perspectivas en Turismo, (25), 88-109.

Carmona-Díaz, G., Morales-Mávil, J. E., \& Rodríguez-Luna, E. (2004). Plan de manejo para el manglar de Sontecomapan, Catemaco, Veracruz, México: una estrategia para la conservación de sus recursos naturales. Madera y Bosques, 10(2), 5-23.

Chávez, G. (2007). Percepción del ecosistema por la comunidad de San Crisanto en Yucatán de acuerdo con su actividad. Cuicuilco, 12(39), 99-114.

Doumet, N. Y., Rivera, M., \& García, N. (2018). Biocorredores como herramientas para el manejo sostenible de los humedales: el caso La Segua y refugio de vida silvestre Isla Corazón-Fragatas. En: Bosques, Recursos Naturales y Turismo Sostenible (pp. 30-52). Manabí, Ecuador: Centro de Investigación y Desarrollo (CIDE).

Fernández, Y. (2008). ¿Por qué estudiar las percepciones ambientales? Una revisión de la literatura mexicana con énfasis en áreas naturales protegidas. Espiral. Estudios sobre Estado y Sociedad, 15(43), 179-202.

Fernández, R., Porter-Bolland, L., \& Sureda, J. (2010). Percepciones y conocimientos ambientales de la población infantil y juvenil de una 


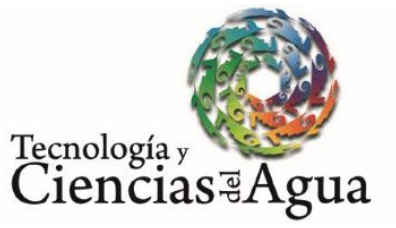

comunidad rural de Veracruz, México. Revista de Educación y Desarrollo, (12), 35-43.

Fisher, R. J., Maginnis, S., Jackson, W. J., Barrow, E., \& Jeanrenaud, S. (2005), Poverty and conservation: Landscapes, People and Power. Gland, Suiza: Unión Internacional para la Conservación de la Naturaleza (IUCN).

Font, X., Cochrane, J., \& Tapper, R. (2004). Tourism for protected area financing: Understanding tourism evenues for effective management plans. Leeds, UK: Universidad Metropolitana de Leeds.

Holladay, P. J., \& Powell, R. B. (2013). Resident perceptions of socialecological resilience. Journal of Sustainable Tourism, 21(8), 11881211.

Idelhadj, A., Rivera-Mateos, M., \& Rodríguez-García, L. (2012). Turismo responsable, espacios rurales y naturales y cooperación para el desarrollo: a propósito de la "Declaración de Tetuán" (Marruecos). Pasos: Revista de Turismo y Patrimonio Cultural, 10(5), 651-664.

Iza, A. (2004). Developments under the Ramsar Convention: Allocation of water for river and Wetlands Ecosystems, Review of European Community \& International Environmental Law, 13(1), 40-46.

Jiménez, C., \& Castillo, M. (2014). Sosteniendo al turismo o turismo sostenible. Estudios y Perspectivas en Turismo, 23(2), 376-395.

Konu, H., \& Kajala, L. (2012). Segmenting protected area visitors based on their motivations. Nature Protection Publications by Mets Cahallitus. Series A 194. Vantaa, Finland: Mets€ahallitus. 


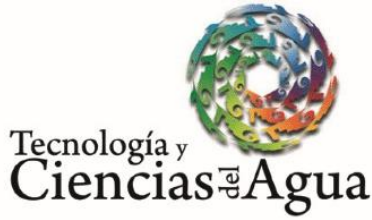

Recuperado

https://julkaisut.metsa.fi/assets/pdf/lp/Asarja/a194.pdf

Malek, M. J., \& Powell, R. B. (2017). Ecotourism resilience to climate change in Dana Biosphere Reserve, Jordan. Journal of Sustainable Tourism. DOI: 10.1080/09669582.2017.1360893

Manson, R. H., \& Moreno-Casasola, P. (2007). Los servicios ambientales que proporciona la zona costera. En: Moreno-Casasola, P., Peresbarbosa, E., \& Travieso-Bello, E. C. (eds.). Estrategias para el manejo costera integral: el enfoque municipal (pp. 319-348). Veracruz, México: Instituto de Ecología (INECOL)-Gobierno del Estado de Veracruz.

Marín-Muñiz, J. L., Hernández-Alarcón, M. E., Rivera, S. E., \& MorenoCasasola, P. (2016). Percepciones sobre servicios ambientales y pérdida de humedales arbóreos en la comunidad de Monte Gordo, Veracruz. Madera y Bosques, 22(1), 53-69.

Martínez, J. (2013). La sostenibilidad en el sector turístico: del marco ambiental global al marco económico-social local. DELOS: Desarrollo Local Sostenible, 6(17). Recuperado de http://www.eumed.net/rev/delos/17/sostenibilidad-sectorturistico.html

Martínez, R., Huber, E., Arredondo, J., Costero, M., \& Peña, F. (2012). Análisis del concepto de sostenibilidad en la legislación mexicana usando el paradigma de desarrollo. Revista Interciencia, 37(2), 107-108. 


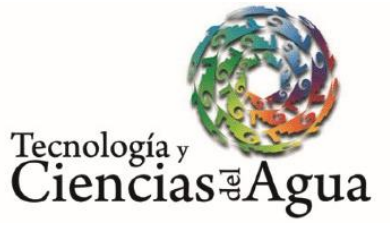

2021, Instituto Mexicano de Tecnología del Agua

Open Access bajo la licencia CC BY-NC-SA 4.0

(https://creativecommons.org/licenses/by-nc-sa/4.0/)

Ministerio del Ambiente de Ecuador. (2014). Evaluación de efectividad de manejo del patrimonio de áreas naturales. Quito, Ecuador: Gobierno de Ecuador.

Ministerio del Ambiente de Ecuador. (2013). Manual para la gestión operativa de las áreas protegidas de Ecuador. Quito, Ecuador: Gobierno de Ecuador.

Molina, E. (2012). Estudio comparativo de los sitios Ramsar en el Ecuador como oferta turística del patrimonio natural del Ecuador. RICIT, (3), 45-81.

Moreno-Casasola, P., Salinas, G., Amador, L., Juárez, L., Cruz, H. C., Travieso-Bello, A. H., Ruelas, L., Moroy, R., Infante, D., LópezRosas, H., Peralta, K., Paradowsca, A., \& Valencia, J. (2006). El proyecto comunitario de conservación, poblamiento y territorio. En: Moreno-Casasola, P. (ed.). Entornos veracruzanos: la costa de La Mancha (pp. 493-536). Xalapa, México: Instituto de Ecología, A.C.

Mulero, A., \& Rivera, M. (2018). Turismo de naturaleza y espacios naturales protegidos en España. Abaco: Revista de cultura y ciencias sociales, (98) (ejemplar dedicado a: El turismo. Desarrollo, transformación y controversia de un fenómeno social), 84-96.

Nunes-da-Cunha, C., Fernández, Ma. T., \& Junk, W. (2014). Classificação e delineamento das Áreas Úmidas Brasileiras. Culabá, Brasil: Federal University of Mato Grosso (UFMT).

OMT, Organización Mundial del Turismo. (2018). El turismo y los Objetivos de Desarrollo Sostenible. Buenas prácticas en las Américas. Madrid, 


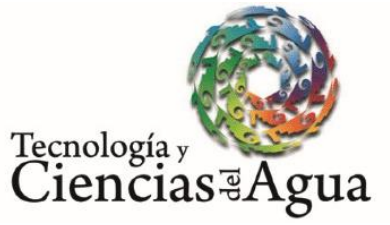

España: Organización Mundial del Turismo y Organización de los Estados Americanos.

OMT, Organización Mundial del Turismo. (2004). Tourism and Poverty Alleviation. Recommendations for Action. Madrid, España: Organización Mundial del Turismo.

Orgaz-Agüera, F. (2014). El Ecoturismo en los humedales: análisis de las potencialidades de República Dominicana. Rosa dos Ventos Recuperado de http://www.redalyc.org/articulo.oa?id $=473547039002$

Papayannis, T. (2002). Regional action for wetlands: the Mediterranean experience 1991-2002. Le Sambuc, France: A MedWet / Tour du Valat Publication.

Puhakka, K., Pitkänen, R., \& Pirkko, S. (2016). The health and well-being impacts of protected areas in Finland. Journal of Sustainable Tourism. DOI:10.1080/09669582.2016.1243696.

República del Ecuador. (2017). Plan Nacional del Buen Vivir, 2017-2021. Quito, Ecuador: Secretaría Nacional de Planificación y Desarrollo, Gobierno del Ecuador.

Sánchez-Carrillo, M., Álvarez-Cobelas, S., Cirujano, M., CarrascoRedondo, A., \& Díaz-Cambronero, L. (2015). La investigación y seguimiento ecológico a largo plazo (LTER). Madrid, España: Revista Ecosistemas.

Scott, A., Cohen, G., Prayag, M., \& Moital, M. (2014). Consumer behavior in tourism: Concepts, influences and opportunities. Current Issues 


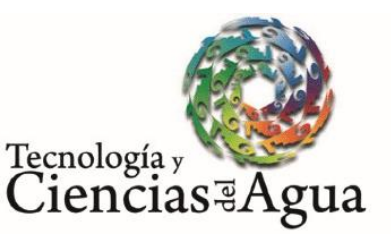

in

\section{$10.1080 / 13683500.2013 .850064$}

2021, Instituto Mexicano de Tecnología del Agua

Open Access bajo la licencia CC BY-NC-SA 4.0

(https://creativecommons.org/licenses/by-nc-sa/4.0/)

Secretaría de la Convención Ramsar. (2016). An Introduction to the Convention on Wetlands. Gland, Switzerland: Ramsar Convention Secretariat.

Secretaría de la Convención Ramsar. (2012). Definición de "humedales" y Sistema de Clasificación de Tipos de Humedales de la Convención Ramsar. Recuperado de http://archive.ramsar.org/cda/es/ramsardocuments-guidelines-classification-system/main/ramsar/1-31105\%5E21235_4000_2.

Serrano, D. (2012). Humedales Ramsar en España. Reflexiones a propósito de su trigésimo aniversario. Investigaciones Geográficas, $57,129-148$.

Shone, M. C., Simmons, D. G., \& Dalziel, P. (2016). Evolving roles for local government in tourism development: A political economy perspective, Journal of Sustainable Tourism. DOI: 10.1080/09669582.2016.1184672

Steck, B. (1999). Sustainable tourism as a development option, practical guide for local planners and decision makers. Eschborn, Germany: GTZ.

SNV, Organización de Desarrollo de los Países Bajos. (2001). SNV and sustainable tourism. Background paper. La Haya, Países Bajos: Organización de Desarrollo de los Países Bajos SNV. Recuperado de http://www.snvworld.org/cds/rgTUR/ 


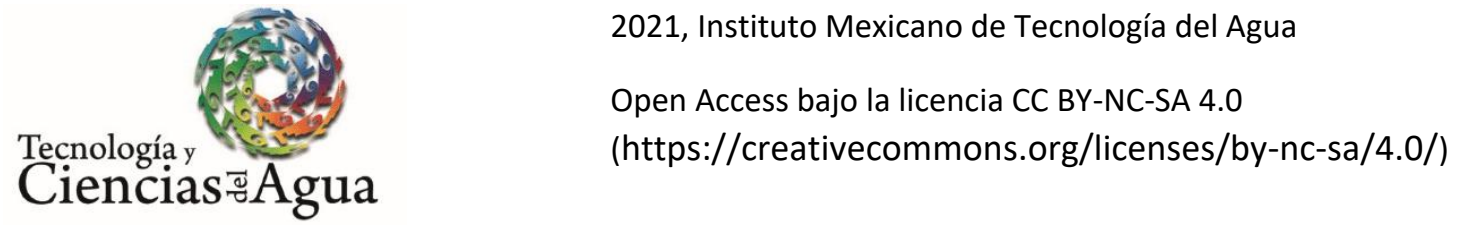

Torres, M. (2012). Sitios Ramsar en Ecuador. Quito, Ecuador: Departamento de Biodiversidad, Ministerio del Ambiente.

Toselli, C., \& Mazza, C. (2014). Planes estratégicos de turismo para el desarrollo local. Una propuesta de análisis a partir del método de los "interrogantes fundamentales". Revista Investigaciones Turísticas, (9), 46, ss.

Van-der-Duim, R., \& Henkens, R. (2007). Humedales, reducción de la pobreza y desarrollo del turismo sostenible: oportunidades $y$ limitaciones. Wageningen, Países Bajos: Wetlands International.

Varisco, C. A. (2016). Turismo Rural: Propuesta Metodológica para un Enfoque Sistémico. Pasos. Revista de Turismo y Patrimonio Cultural, 14(1), 153-167.

Vera, J., \& Marchena, M. (2014). Turismo y desarrollo: un planteamiento actual. Cuadernos de Turismo, (3), 53-98.

Vera-Rebollo, J. F., \& Díez-Santo, D. (2016). Espacios y destinos turísticos. Canelobre: Revista del Instituto Alicantino de Cultura "Juan GilAlbert", 66 (ejemplar dedicado a: El turismo en Alicante y la Costa Blanca), 84-97. 